\title{
WIND SPEED, STABILITY AND EDDY VISCOSITY OVER MELTING ICE SURFAGES
}

\author{
By M. E. Grainger and H. Lister \\ (Department of Geography, University of Newcastle upon Tyne, Newcastle upon Tyne, \\ England.)
}

\begin{abstract}
AвsTRact. The laws of wind-speed variation with height and their modification with stability are discussed and applied to observations in the first $2 \mathrm{~m}$. over various cold surfaces. An exponential law is superior save in frequent, near-neutral conditions, but the logarithmic law is superior in neutral and again in really stable conditions. A power law and a logarithmic-plus-linear law give the best fit with the data only at moderate stabilities. A logarithmic-plus-cubic law of wind speed is evolved that permits suppression of linear additions to the logarithmic law at two distinct stabilities. A power form of variation of Richardson number with height is found and compared with a linear form. The former is applied with the logarithmicplus-cubic law to the observed data, though with limited success. Eddy-viscosity coefficients for the different laws are compared.
\end{abstract}

RÉsumé. Vitesse du vent, stabilité et coefficient de viscosité au-dessus de surfaces de glace en période de fonte. Les lois de variation de la vitesse du vent en fonction de la hauteur et leur modification par stabilité sont discutées et appliquées aux observations dans les deux premiers mètres au-dessus de surfaces froides variées. Une loi exponentielle est meilleure sauf dans des conditions fréquentes presque neutres, mais la loi logarithmique est meilleure dans des conditions neutres et aussi dans des conditions réellement stables. Une fonction de puissance ou une fonction logarithmique plus linéaire donne un meilleur accord avec les données seulement à des stabilités modérées. Une loi logarithmique plus cubique (troisième degré) de la vitesse du vent est developée qui permet l'amortissement des additions linéaires à la loi logarithmique à deux stabilités. Une fonction de puissance de la variation du nombre de Richardson avec la hauteur est établie et comparée avec une fonction linéaire. La première est appliquée aux données observées avec une fonction logarithmique plus cubique mais avec un succès limité. Les coefficients de viscosité pour les différentes fonctions sont comparés.

Zusammenfassung. Windgeschwindigkeit, Stabilität und Wirbelviskosität über schmelzenden Eisflächen. Es werden die Gesetze für die Änderung der Windgeschwindigkeit mit der Höhe und ihre Modifikation bei sich ändernder Stabilität diskutiert und auf Beobachtungen in den untersten zwei Metern über verschiedenen Kaltflächen angewandt. Ausser unter den häufigen fast-neutralen Bedingungen ist eine Exponentialfunktion zutreffend, doch in neutralen und dann wieder in wirklich stabilen Lagen überwiegt das logarithmische Gesetz. Nur bei mässigen Stabilitäten stimmen ein Potenzgesetz und ein logarithmisches Gesetz mit linearem Zusatzglied mit den Daten am besten überein. Es wird ein log-mit-kubisch-Gesetz für die Windgeschwindigkeit entwickelt, das bei zwei bestimmten Stabilitäten lineare Hinzufügungen zum logarithmischen Gesetz überflüssig macht. Eine Potenzfunktion für die Änderung des Richardson-Index mit der Höhe wird hergeleitet und mit einer linearen Funktion verglichen. Die erste wird zusammen mit dem log-mit-kubisch-Gesetz auf die Beobachtungsdaten angewandt, jedoch mit begrenztem Erfolg. Die Wirbelviskositätskoeffizienten der verschiedenen Gesetze werden miteinander verglichen.

THE transfer of heat, water vapour and momentum between the atmosphere and the ground govern many of the physical processes enacted at the Earth's surface. The rate of diffusion of properties of the atmosphere by means of turbulence at the Earth's boundary layer is expressed by transfer coefficients. If there is a certain identity in the vertical profiles of these properties, the transfer coefficients for heat, for water vapour and for momentum are assumed equal, the last being evaluated from measurement of the variation of wind speed with height. The form of the vertical profile of wind speed depends upon the physical characteristics of the surface and the stability in the atmosphere over it. Air stability is expressed as a ratio of the buoyancy forces to the inertial forces and may become so strongly positive that wind eddies are suppressed near the surface - say in the lowest one or two metres of air. Something near to this condition is experienced frequently over a melting ice surface which thus offers an ideal opportunity for measurement of the range of turbulent mixing to correlate with stability and hence find the exchange coefficients.

With the inherent difficulties of subjecting meteorological conditions to laboratory techniques, most of the equations postulated as expressing the increase of wind speed with height, have arisen empirically. Essentially, a universal law is sought which is applicable throughout 
the range of stabilities normally experienced in the surface layer of the atmosphere; the law should not be so complex that it is generally impracticable. This paper considers the laws of wind-speed variation with height in relation to available detailed measurements of wind speed and temperature in the lowest $2 \mathrm{~m}$. over various snow and ice surfaces.

\section{Notation}

The following symbols and abbreviations are used:

$$
\begin{aligned}
& a, c \quad \text { constants for specific ranges of stability } \\
& B \quad \text { inverse of a stability length }=\frac{g}{T_{0}} \frac{\left(T_{3}-T_{1}\right)}{u_{2}{ }^{2}}\left(\mathrm{~cm} .^{-1}\right) \\
& c_{p} \quad \text { specific heat of air at constant pressure } \\
& f(n) \quad \text { function of } n \\
& g \quad \text { acceleration due to gravity }\left(\mathrm{cm} . \mathrm{sec}^{-2}\right) \\
& H \quad \text { turbulent heat flux }=\rho c_{p} K_{H} \frac{d T}{d z}\left(\text { cal. cm. } .^{-2} \text { sec. }^{-1}\right) \\
& k \quad \text { von Kármán's constant } \approx 0.4 \\
& K_{M} \quad \text { eddy coefficient of momentum (eddy viscosity) }\left(\mathrm{cm}^{2} \mathrm{sec}^{-1}\right) \\
& \kappa_{M}{ }^{*} \quad \text { dimensionless eddy viscosity }=\frac{\kappa_{M}}{u_{*} z} \\
& K_{H} \quad \text { eddy coefficient of heat (eddy conductivity) }\left(\mathrm{cm}^{2}{ }^{2} \mathrm{sec}^{-\mathbf{I}}\right. \text { ) } \\
& l \quad \text { mixing length } \\
& l_{\mathrm{I}} \quad \text { mixing length at height } z_{\mathrm{I}} \\
& L \quad \text { stability length }=\frac{u_{*}{ }^{3} T_{o} c_{p} \rho}{k g H}(\mathrm{~cm} .) \\
& L^{\prime} \quad=-\frac{u_{*} T_{\circ} \frac{d u}{d z}}{k g \frac{d T}{d z}}=-\frac{\kappa_{H} L}{K_{M}}(\mathrm{~cm} .) \\
& n \quad \text { power parameter }>\mathrm{I} \\
& p \quad \text { power parameter } \\
& r \quad \text { linear dimension of object, e.g. radius of sphere in fluid or of pipe carrying } \\
& \text { the fluid (cm.) } \\
& \text { Re } \quad \text { Reynolds number }=\frac{r v}{v} \\
& \mathrm{Ri} \quad \text { Richardson number }=\frac{g\left(\frac{d T}{d z}+\Gamma\right)}{T_{\mathrm{o}}\left(\frac{d u}{d z}\right)^{2}}, \quad\left(\Gamma \text { is omitted when } \ll \frac{d T}{d z}\right) \\
& \mathrm{Ri}_{\mathrm{f}} \quad \text { flux form of } \mathrm{Ri}=\frac{K_{H}}{K_{M}} \frac{g}{T_{\mathrm{o}}} \frac{d T / d z}{(d u / d z)^{2}} \\
& \mathrm{Ri}_{z} \quad \text { Richardson number at height } z \\
& s \quad \text { standard height }(\mathrm{cm} .) \\
& S \quad \text { stability index (after Deacon) }=\frac{T_{2}-T_{\mathrm{I}}}{\left(u_{\mathrm{I}} \cdot 5\right)^{2}}\left({ }^{\circ} \mathrm{K} . \mathrm{cm}^{-2} \mathrm{sec}^{-2}\right) \\
& \mathcal{T} \text { air temperature }\left({ }^{\circ} \mathrm{K}\right. \text {.) }
\end{aligned}
$$




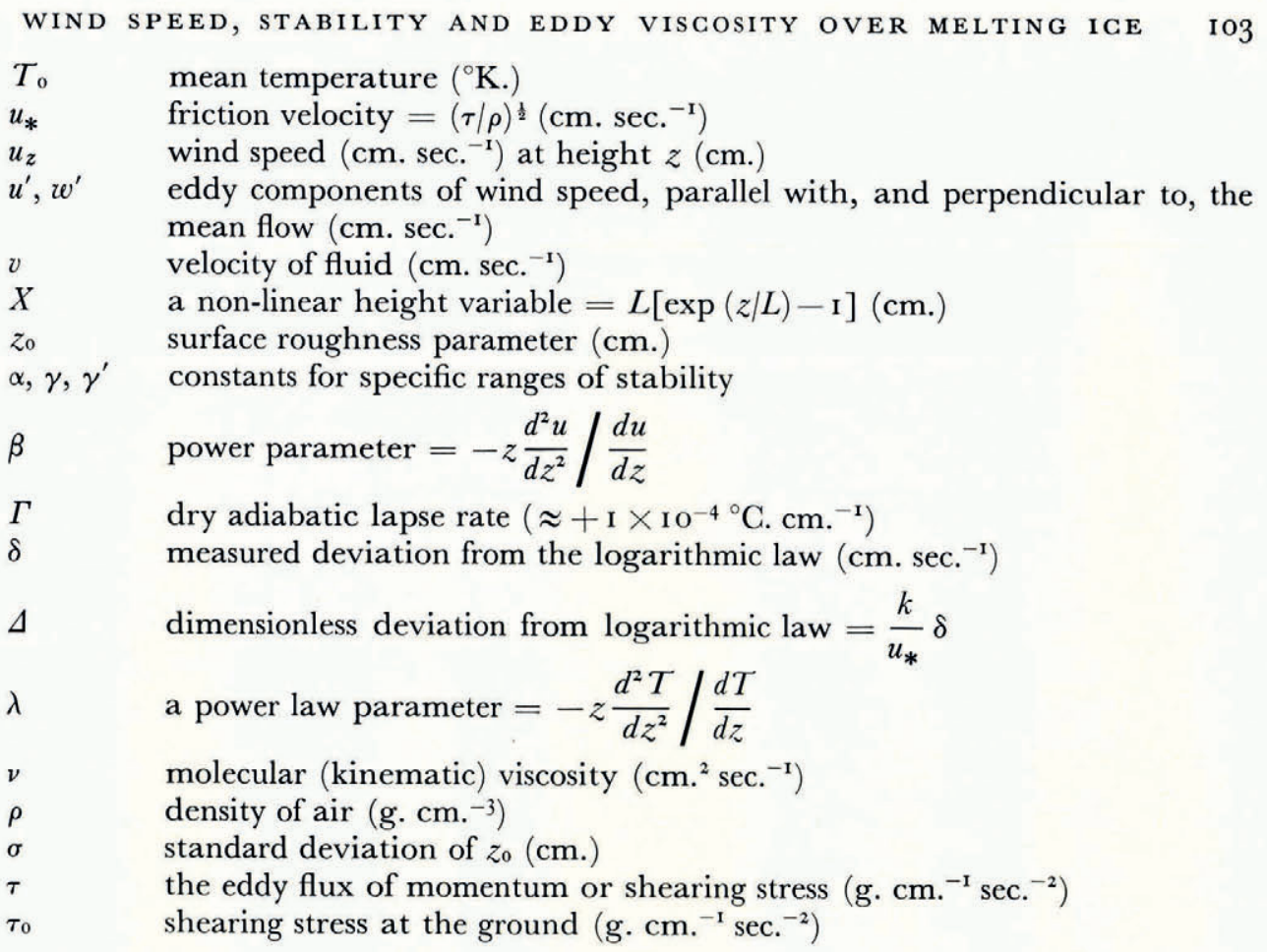

I Review of Existing Laws

\section{(a) The logarithmic law}

Experiments with fluids of uniform density distribution, in pipes and over flat plates, indicate that the velocity varies as the logarithm of the distance from the boundary. This relationship is applicable over smooth or rough surfaces with turbulent flow, which may be recognized by fairly high Reynolds numbers $\left(\mathrm{Re}>75 \times 10^{5}\right)$. For the atmosphere, there is no adequate definition of the characteristic length required by the Reynolds number but turbulent flow prevails. In a neutral atmosphere, i.e. when the vertical profile of air temperature is governed only by change in pressure, the vertical wind profile appears to follow a logarithmic distribution. Many observers have found that the logarithmic law is applicable over a fairly wide stability range (Brunt, I939, p. 247), but becomes less satisfactory (Fig. I) as stabilities depart from neutral (Pasquill, I949[a], p. 124).

The mixing-length hypothesis, though somewhat discredited, has not been replaced by any very satisfactory approach. That hypothesis postulates that $l$ is a unique length which characterizes the local intensity of turbulent mixing (Sutton, I953, p. 73). Fundamentally the logarithmic law rests on the assumption that velocity fluctuations in both vertical and horizontal directions are identically proportional to the wind-speed gradient, i.e.

The shear stress $\tau=-\rho \overline{u^{\prime} w^{\prime}}=\rho l^{2}\left(\frac{d u}{d z}\right)^{2}$.

$$
u^{\prime}=w^{\prime}=l \frac{d u}{d z} .
$$

With the supposition that $l$ varies linearly with height $(l=k z)$

$$
\frac{d u}{d z}=\left(\frac{\tau}{\rho}\right)^{\frac{1}{2}} \frac{\mathrm{I}}{k z}=\frac{u_{*}}{k z} .
$$


The constant introduced on integration is a measure of the surface roughness, being the height $\left(z_{0}\right)$ at which the wind speed is zero and hence incorporated in the logarithmic law generally expressed as

and, since the wind shear

$$
u=\frac{u_{*}}{k} \ln \frac{z}{z_{0}}
$$

the eddy viscosity

$$
\tau=\rho K_{M} \frac{d u}{d z}
$$

$$
\kappa_{M}=k^{2} z^{2} \frac{d u}{d z}=k u_{*} z .
$$

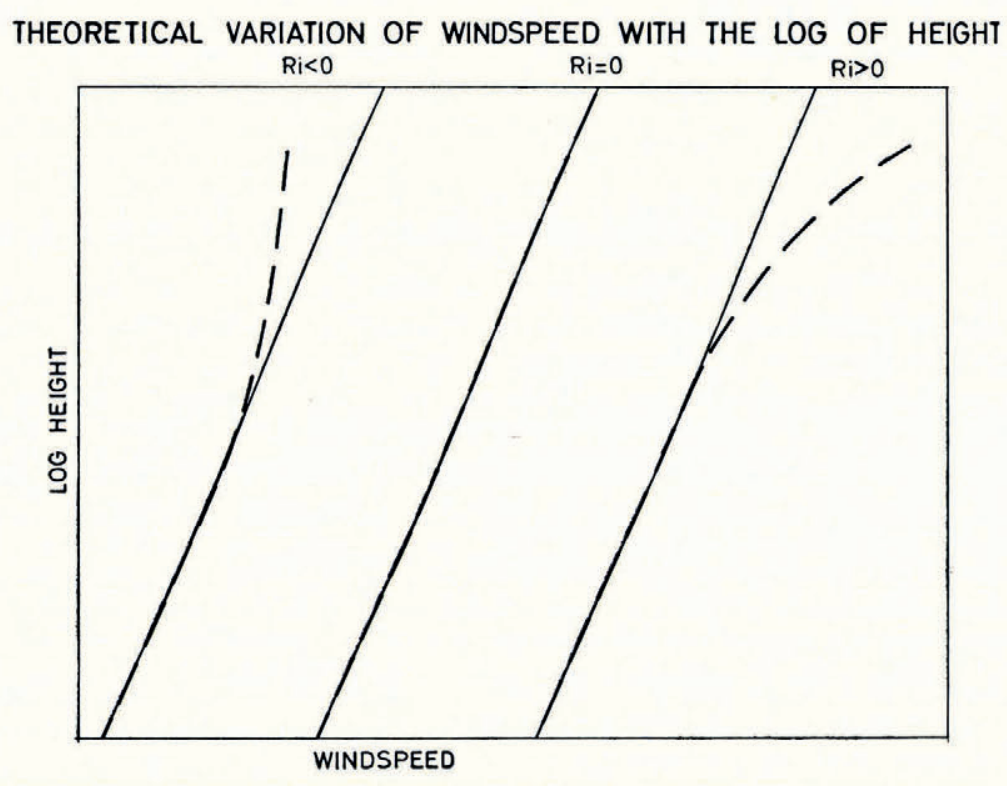

(b) Power laws

Fig. I. Effect of stability on the variation of wind speed with height

A less exact expression has been evolved, similarly from pipe flow, relating velocity with a fractional power of the distance from the boundary. The power parameter may be modified to extend the applicability of the law through the whole range of stability. Since this power reflects surface roughness also, it is not an independent index of stability. Over grassland, the power varies from $\frac{1}{6}$ in stable, through $\frac{1}{7}$ in neutral, to $\frac{1}{12}$ in unstable conditions (Sutton, I932, p. 74). In work on heat and vapour transfer over glacier surfaces the power law has been favoured by a number of workers (e.g. Wallén, I948, p. 572) after being applied most successfully by Sverdrup over snow surfaces (Sverdrup, 1936, p. I4):

therefore

$$
\begin{aligned}
u & =u_{\mathrm{I}}\left(\frac{z}{z_{\mathrm{I}}}\right)^{\mathrm{I} / n} \\
\frac{d u}{d z} & =\frac{u_{\mathrm{I}}}{n}\left(\frac{z}{z_{\mathrm{I}}}\right)^{\frac{\mathrm{I}}{n}-\mathrm{I}}
\end{aligned}
$$

$$
K_{M}=f(n)\left(u_{\mathrm{I}} z_{\mathrm{I}}\right)^{\frac{n-1}{n+1}}\left(\frac{z}{z_{\mathrm{I}}}\right)^{\frac{n-1}{n}} .
$$


This simple power law is not now used since it does not incorporate the friction velocity $u_{*}$ nor the surface roughness parameter $z_{0}$ and the power index can be most unsatisfactory. To overcome these difficulties Deacon advanced empirically, a systematic power parameter which would account for observed deviations from the logarithmic law in non-neutral stability and be applicable to all stability ranges (Deacon, I949). In addition, the power is independent of surface roughness.

The velocity profile is represented by

$$
u=\frac{u_{*}}{k(\mathrm{I}-\beta)}\left[\left(\frac{z}{z_{0}}\right)^{\mathrm{I}-\beta}-\mathrm{I}\right]
$$

where $\beta>\mathrm{I}$ in unstable conditions, $\beta<\mathrm{I}$ in stable conditions, and $\beta=\mathrm{I}$ in neutral stability when the expression reduces to the logarithmic law. The eddy viscosity becomes

$$
K_{M}=k u_{*} z\left(\frac{z}{z_{0}}\right)^{\beta} \text {. }
$$

Priestley states (I959, p. 30) that Deacon's law is the simplest and most widely used; Dalrymple and others (1963, p. I3) applied Deacon's law to analysis of micro-meteorological data at the South Pole; this power law is, however, not satisfactory for a very stable atmosphere.

(c) Logarithmic-plus-linear laws

Holzman and earlier workers such as Rossby and Montgomery (Sutton, 1953, p. 265) suggested incorporating a function of stability into the logarithmic law. Monin and Obukhov ( 1954 , p. 6 of translation) added a function of height and stability for the deviation from the logarithmic form;

$$
\frac{d u}{d z}=\left(\frac{\tau}{\rho}\right)^{\frac{1}{2}} \frac{\mathrm{I}}{k z} F\left(\frac{z}{L}\right) .
$$

The function $F$ was expanded as a simple power series in terms of $z / L$ and the first two terms used

$$
F\left(\frac{z}{L}\right) \approx \mathrm{I}+\alpha \frac{z}{L}
$$

Stability is expressed as the ratio of wind shear, represented by the momentum flux, to the buoyancy forces represented by the heat flux and opposed by gravity. The Richardson number (see notation) is generally used as a parameter of stability but since this involves drawing tangents to vertical profiles of temperature and of wind speed, simpler expressions are frequently adopted. Monin and Obukhov expressed stability as

$$
B=\frac{g}{T_{0}} \frac{T_{3}-T_{1}}{u_{2}^{2}}
$$

which gives dimensions of inverse length. For use in the wind-speed expression, by combining all the appropriate elements of the flux equations:

the wind shear

$$
\tau=\rho K_{M} \frac{d u}{d z}
$$

the heat flux

$$
H=-c_{p} \rho K_{H} \frac{d T}{d z}
$$

and

$$
\frac{g}{T_{0}},
$$


Monin and Obukhov found a stability length

$$
L=u_{*}{ }^{3} / \frac{-k g}{T_{\mathrm{o}}} \frac{H}{c_{p} \rho} .
$$

This was used in the wind-profile equation from (8)

which produces an eddy viscosity

$$
u=\frac{u_{*}}{k}\left[\ln \frac{z}{z_{0}}+\frac{\alpha_{z}}{L}\right]
$$

$$
K_{M}=k u_{*} z\left(\mathrm{I}+\alpha \frac{z}{L}\right)^{-1} .
$$

These expressions assume, from the apparent similarity of the temperature and wind-speed profiles, that the exchange coefficients for heat and momentum, if not identical, vary with height at a constant rate, i.e. $K_{H} / K_{M}=$ constant. Without actual heat flux measurements, the characteristic stability length $L$ and the universal constant $\alpha$ may be found only by regression involving the modified Richardson number, $B$. Assuming that temperature can also be expressed similarly to (ro) then

where

$$
B=\frac{\mathrm{I}}{\alpha} f\left(\frac{\alpha}{L}\right)
$$

$$
f\left(\begin{array}{c}
\alpha \\
L
\end{array}\right)=\frac{\alpha\left[\ln \left(z_{3} / z_{1}\right)+(\alpha / L)\left(z_{3}-z_{\mathrm{I}}\right)\right]}{L\left[\ln \left(z_{2} / z_{0}\right)+(\alpha / L) z_{2}\right]^{2}}
$$

and $\alpha / L$ can be determined from three wind speeds using equation (10). Monin and Obukhov, using data from more than 800 profiles, through a stability range, indicated by $B$, from -0.084 to 0.015 , found $\alpha=+0.62$. They suggest other functions might be more suitable outside a moderate stability range. Recently Taylor ( 1960, p. 77) found that different constants for various stability regimes are more suitable as indicated by Table I. In conditions of free convection (temperature lapse), which are infrequent over melting ice surfaces, Taylor considers that this logarithmic-plus-linear law does not apply.

Table I. Values derived from Observations over Grassland OF THE Logarithmic-Plus-Linear LaW constant $\alpha$

(after Taylor, 196o, p. 77; Deacon, 1962, p. 3171; Monin and Obukhov, 1954, p. 20).

$\left.\begin{array}{cccccc}\begin{array}{c}\text { Temperature } \\ \text { Regime }\end{array} & \multicolumn{3}{c}{\text { Value of a found by } \text { Taylor }} & \multicolumn{2}{c}{\begin{array}{c}\text { Value of a } \\ \text { by: }\end{array}} \\ \begin{array}{cccc}\text { from data by: } \\ \text { Adiabatic }\end{array} & \text { Rider } & \text { Swinbank } & \begin{array}{c}\text { Monin and } \\ \text { Obukhov }\end{array} & \text { Deacon } & \begin{array}{c}\text { Monin and } \\ \text { Obukhov }\end{array} \\ \text { Inversion } & 12 & 6 & 6 & 3 & \end{array}\right\} 0.6$

Ellison (1957, p. 46r) employs a modified form of the momentum coefficient

from equations (I) and (3)

$$
\kappa_{M}^{*}=\frac{\kappa_{M}}{u_{*} z}
$$

$$
\begin{aligned}
& =\frac{u_{*}}{k\left(\frac{d u}{d z}\right)} \\
& =k f\left(\frac{z}{L}\right)=\frac{L}{z} \mathrm{Ri}_{\mathrm{f}}
\end{aligned}
$$


to determine the function $f\left(\frac{z}{L}\right)$ in terms of the conditions which occur at extreme atmospheric stability. If $K_{M}{ }^{*}=k$ at $\mathrm{Ri}_{\mathrm{f}}=0, K_{M} *=0$ at $\mathrm{Ri}_{\mathrm{f} \text { crit. }}$, i.e. at very high stability. Ellison's expression for wind speed

$$
\left(\frac{\kappa_{M} *}{k}\right)^{4}=\mathrm{I}-\frac{\kappa_{M} * z}{\gamma k L}
$$

approximates to a logarithmic-plus-linear law

$$
u=\frac{u_{*}}{k}\left[\ln \frac{z}{z_{0}}+\frac{\gamma}{4} \frac{\left(z-z_{0}\right)}{L}\right]
$$

where $\frac{\gamma}{4}=\frac{k}{{ }_{4} \mathrm{Ri}_{\mathrm{f}_{\text {crit. }}}}=\alpha$ in Monin and Obukhov's expression (10).

Using Rider's data, Ellison finds $\alpha=0.8$ which compares with $\alpha=0.6$ by Monin and Obukhov. To overcome the lack of absolute measurement of fluxes, Panofsky and others (196o, p. 39o) suggest

and

$$
L^{\prime}=-\frac{\kappa_{H}}{K_{M}} L=-\frac{u_{*} T_{0}(d u / d z)}{k g(d T / d z)}
$$

Expression (14) becomes

$$
\gamma^{\prime}=\frac{\kappa_{H}}{\kappa_{M}} \gamma
$$

$$
u=\frac{u_{*}}{k}\left[\ln \frac{z}{z_{\mathrm{o}}}-\frac{\gamma^{\prime}}{L^{\prime}}\left(z-z_{0}\right)\right]
$$

and the eddy viscosity

$$
K_{M}=k u_{*} z\left(\mathbf{I}-\frac{\gamma^{\prime}}{4} \frac{z}{L^{\prime}}\right) .
$$

The stability length $L^{\prime}$ associated with this variation of the logarithmic-plus-linear law may be defined in terms of actual gradients of wind speed and temperature. This avoids dependence on stability indices or actual heat-flux measurements, but places heavy reliance on the graphical construction of the profiles. Observational data appear to indicate a constant $\gamma^{\prime}=\mathrm{I} 8$ for all except very stable conditions (Panofsky and others, ig6o, p. 393). In such conditions, Panofsky and others suggest that factors not considered in the similarity theory may become important. Yamamoto (1959, p. 68) using Rider's data over short grassland, found $\gamma^{\prime}=+56$ in unstable and neutral conditions and, less distinctively, $\gamma^{\prime}=+7 \cdot 3$ in a stable atmosphere.

An equation of similar logarithmic-plus-linear form has been suggested to account for deviations of wind speed from its variation with the logarithm of height, especially in inversion conditions (Liljequist, I957, p. 212). However, as Liljequist suggests, a large vertical range of observational data (up to Io m.) is required for the definite recognition of the deviation; it is scarcely possible for observations limited to the lowest 2 metres.

\section{(d) Exponential law}

To account for the change of shape of the wind profiles as indicated in Figure I, Swinbank ( 1964, p. 120) introduces into the form of the wind velocity gradient at neutral stability

$$
\frac{d u}{d z}=\frac{u_{*}}{k z}
$$


a variable $X$ which should be a function of heat and momentum fluxes as well as height

$$
\frac{d u}{d X}=\frac{u_{*}}{k X} .
$$

Swinbank expresses the kinetic energy of turbulence in terms of the shearing stress and the buoyancy

$$
\tau \frac{d u}{d X}=\tau \frac{d u}{d z}+\frac{g H}{c_{p} T}
$$

from which the non-linear height $X$ is evolved in terms of $L$

The wind gradient then becomes

$$
X=L\left[\left(\frac{z}{L}\right)-\mathrm{I}\right] \text {. }
$$

$$
\frac{d u}{d z}=\frac{u_{*}}{k L}\left[\mathrm{I}-\exp \left(-\frac{z}{L}\right)\right]^{-1},
$$

from which the difference between two wind speeds

$$
u_{2}-u_{\mathrm{I}}=\frac{u_{*}}{k} \ln \left[\frac{\exp \left(z_{2} / L\right)-\mathrm{I}}{\exp \left(z_{\mathrm{I}} / L\right)-\mathrm{I}}\right] .
$$

With a value for $k$ and wind-speed observations at three heights, the length $L$ and the friction velocity $u_{*}$ can be evaluated.

Swinbank (1964, p. 123) shows that small errors in $k$ (generally taken as $=0.4$ ) can be significant. Errors in $u_{*}$ will be equally significant; so to avoid these the measurements at three heights are expressed as

$$
\frac{u_{3}-u_{\mathrm{I}}}{u_{2}-u_{\mathrm{I}}}=\frac{\ln \left[\frac{\exp \left(z_{3} / L\right)-\mathrm{I}}{\exp \left(z_{\mathrm{I}} / L\right)-\mathrm{I}}\right]}{\ln \left[\frac{\exp \left(z_{2} / L\right)-\mathrm{I}}{\exp \left(z_{\mathrm{I}} / L\right)-\mathrm{I}}\right]} .
$$

Although Swinbank's exponential expression does not propose any critical value of stability, it transforms to the logarithmic law in slight stabilities.

From (17)

$$
\kappa_{M}=k u_{*} L[\mathrm{I}-\exp (-z / L)] .
$$

\section{Apparatus}

For the observations analysed here, the following apparatus was used :

Cassella-Sheppard sensitive cup anemometers were set up at all the sites. On the Britannia Gletscher, Greenland, they were mounted at 30 , I00, 200 and $400 \mathrm{~cm}$; on Britannia Sø, Greenland, at 6, 10, 30, 100 and $200 \mathrm{~cm}$.; in the Tarfala valley, Sweden, at $10,30,100,200 \mathrm{~cm}$. and on the Storglaciären, Sweden, at 100 and $200 \mathrm{~cm}$. These last, giving the wind run over a half or one hour interval, were a control on mean values of instantaneous wind speeds read successively from hot bulb anemometers mounted at I, 2, 4, 6, 8, I2, 30, 100 and $200 \mathrm{~cm}$. The hot bulb anemometer had been made to reduce the size of the anemometer and obviate errors probable in closely setting the instruments, particularly near the surfaces, for detailed vertical profiles. It comprised a sensistor (a semi-conductor with a high temperature coefficient of resistance) heated by a constant voltage across it and cooled by the air flow, which varied the temperature and hence the bulb resistance, which was in turn measured by amplifying the out-of-balance current of a Wheatstone bridge. For reduction of rapid fluctuations and part protection from the weather, the bulb was mounted vertically at the centre of a fine wire gauze cylinder (Caisley and others, 1963, p. 42). 
In Greenland and at the valley station in Sweden, thermocouples were used to measure profiles of temperature and vapour pressure (Lister and Taylor, I96 I, p. Io). The apparatus was similar to that of Pasquill (1949[b], p. 239). The 28 s.w.g. copper/constantan thermocouples were set in $\frac{1}{8}$ in. $\left(3 \cdot 17 \mathrm{~mm}\right.$.) dia. $\times \frac{1}{2} \mathrm{in} .(\mathrm{I} \cdot 27 \mathrm{~cm}$.) long copper rods to increase the thermal capacity and attenuate the response to rapid fluctuations in temperature. Each pair of couples was arranged as dry- and wet-bulb thermometers shielded from radiation and mounted in an aspirated tubular mast at 2, 6, I0, 30, I00, 200, 300, and 400 cm. A light-point galvanometer was switched in turn between each thermocouple junction and a standard reference junction kept in a vacuum flask of melting ice, the temperature of which was checked from time to time with a spirit thermometer. The galvanometer could be read more quickly than a potentiometer; the eight pairs of thermocouples could be read in one minute.

On Storglaciären, temperature and humidity profiles were measured by resistance thermometers (sensistors), mounted as wet and dry bulbs along a single axis of concentric radiation screens and a small $12 \mathrm{~V}$. motor and fan for aspiration (Caisley and others, I963, p. 39). Fine copper wire was wrapped around each sensistor to lag the response to temperature and humidity changes. Resistance values were obtained with the same Wheatstone bridge used to measure wind speeds. At each of the Storglaciären sites, nine of these compact units were mounted at $\mathrm{I}, 2,4,6,8, \mathrm{I} 2,30, \mathrm{I} 00$ and $200 \mathrm{~cm}$.

Mean profiles of wet- and dry-bulb temperatures were taken from at least six sets of profiles read at approximately equal intervals through one hour. Observations were made during alternate hours for periods varying from 8 to $48 \mathrm{hr}$. on various days in the ablation season at each glacier.

Instruments were interchanged vertically along their respective masts to ensure that any experimental error would not systematically affect the whole series of observations.

Accuracy of the cup anemometers has been given as $2 \mathrm{~cm} . \mathrm{sec}^{-1}$ but on a glacier, verticality of the spindle cannot be perfectly maintained so $\pm 5 \mathrm{~cm} . \mathrm{sec}^{-1}$ is more realistic. The hotbulb anemometers, calibrated in a wind tunnel, had an accuracy of $\pm 8 \mathrm{~cm}$. sec. $^{-1}$; the thermocouples $\pm 0 \cdot 05^{\circ} \mathrm{C}$.; the temperature measuring sensistors $\pm 0.04^{\circ} \mathrm{C}$. The sensistors were found, by recalibration, to have remained stable throughout the period of the field work. Error in height interval between instruments was not more than $0.5 \mathrm{~cm}$. but the coincidence of the height zero with a mean surface was inevitably the most difficult to achieve in the field. From the plotted data, however, the height datum does not seem to be in error by more than $\pm \mathrm{I} \mathrm{cm}$. These errors were not exceeded when drawing vertical profiles, values from which were used in calculations.

\section{Sites Where Observations Were Regorded}

Wind-speed and temperature measurements recorded during the melting season were used from the following sites (the designation numbers are retained in Fig. 2):

I. Tarfala valley, $3.5 \mathrm{~km}$. long, $0.5 \mathrm{~km}$. wide across the bottom of the U-shaped cross-section, runs approx. north-south in the Kebnekaise massif in north Sweden. This hanging valley has three tributary valleys occupied by glaciers, though the main valley is snow-free in summer; it is steep walled and floored by fluvially re-worked moraine with sparse, very short vegetation. The site of observation was on a gentle slope averaging 4 degrees that increased to the east, into the valley wall. Stone fragments and cobbles, interspersed with patches of thin soil and moss were dotted irregularly with 20 to $50 \mathrm{~cm}$. dia. boulders. These last were cleared from the immediate location of the site and were sparse in the direction of the prevailing wind, down-valley. $\bar{z}_{0}=0.4 \mathrm{~cm}$. with standard deviation $\sigma=0.12 \mathrm{~cm}$. Station height I, I IO m. lat. $67^{\circ} 53^{\prime} \mathrm{N}$., long. $18^{\circ} 38^{\prime} \mathrm{E}$.

2. Storglaciären, $3 \mathrm{~km}$. long, $0.8 \mathrm{~km}$. wide, flowing east from the cliff slopes of Kebnekaise, in one of the valleys mentioned above. Two stations were set up approximately on the centre 
line of the glacier surface which had a 4 to 5 degree slope and was snow-covered initially but changed to coarse firn and then largely to smooth ice intersected in places by melt-water channels. Wind over the surface was generally at a small angle to the centre line and more frequently down-glacier. $\bar{z}_{0}=0 \cdot 01 \mathrm{~cm} . \sigma=0.002 \mathrm{~cm}$. Upper Station: height $1,385 \mathrm{~m}$., lat. $67^{\circ} 53^{\prime}$ N., long. $18^{\circ} 35^{\prime}$ E. Lower station: height 1,325 m., lat. $67^{\circ} 53^{\prime}$ N., long. $18^{\circ} 36^{\prime}$ E.

\section{STABILITY}

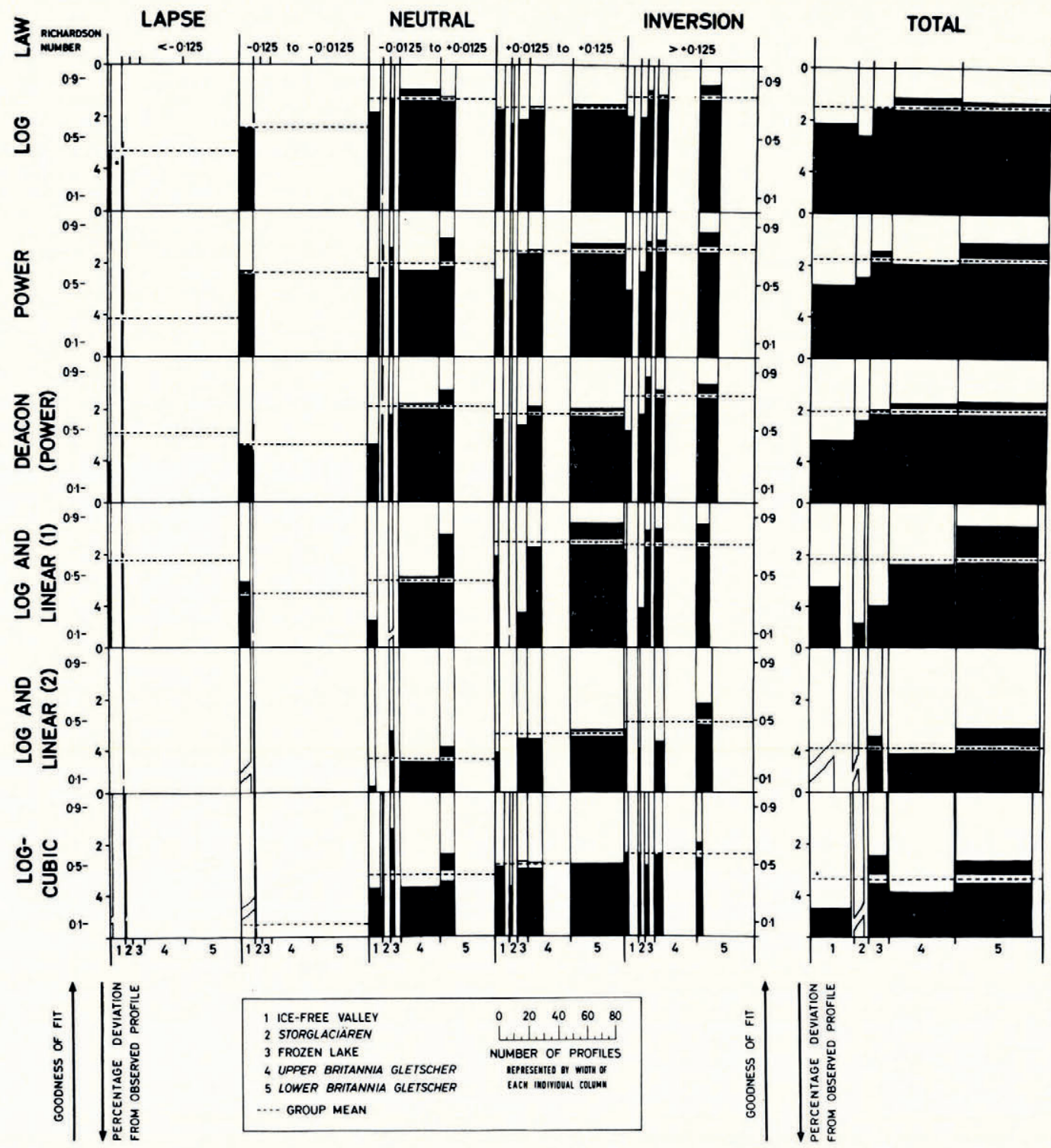

Fig. 2. Mean deviation of wind speeds (observed in the lowest $2 \mathrm{~m}$.) from laws of wind-speed variation with height. The two scales on the ordinates are "goodness of fit" $o$ to $I$ and mean deviation expressed as a percentage of the mean wind speed at $I \mathrm{~m}$. The abscissa scale gives the number of vertical wind profiles for which the respective law was applicable and is divided into groups for different sites; the dotted line gives the mean fit for all sites. The summary on the right indicates the applicability of each law at all stabilities 
Since these stations were $\mathrm{I} \mathrm{km}$. apart with similar surfaces the observations are taken in one group in Figure 2.

3. Britannia Sø, approximately ro $\mathrm{km}$. long, $3 \mathrm{~km}$. wide, is a frozen, ice-dammed lake in north Dronning Louise Land, north-east Greenland. Instruments were sited $200 \mathrm{~m}$. from the northern shore of the lake and operated when the wind was east or west, giving a fetch of approximately $2 \mathrm{~km}$. over the melting ice surface, which had slightly roughened patches where the ice had candled. $\bar{z}_{0}=0.04 \mathrm{~cm} . \sigma=0.005 \mathrm{~cm}$. Station height $223 \mathrm{~m}$., lat. $77^{\circ} 09^{\prime} \mathrm{N}$., long. $23^{\circ} 40^{\prime} \mathrm{W}$.

4. Britannia Gletscher, $14 \mathrm{~km}$. long, $8 \mathrm{~km}$. wide, is a valley glacier flowing south into Dronning Louise Land from the Greenland Ice Sheet. Above the comparatively steep glacier snout, overall slope varied little from 2 degrees. Coarse snow in sastrugi $10-40 \mathrm{~cm}$. high at the beginning of the melt season gave place to undulating wet snow and finally to bare, hummocked ice. The upper station data is representative of conditions on the margin of the inland ice. Apparatus was located $\mathrm{I} \cdot 5 \mathrm{~km}$. from the eastern edge of the glacier but the wind, largely N.N.W., had a fairly uniform fetch of nearly $4 \mathrm{~km} . \bar{z}_{0}=0.7 \mathrm{~cm}$. (early summer $z_{0}=\mathrm{I} \cdot \mathrm{I} \pm$ $0 \cdot 25$, middle summer $z_{0}=0 \cdot 68 \pm 0 \cdot I_{4}$, late summer $\left.z_{0}=0 \cdot 5^{8} \pm 0 \cdot 1_{5}\right)$. Upper Station: height $620 \mathrm{~m}$., lat. $77^{\circ} \mathrm{I} 4^{\prime} \mathrm{N}$., long. $23^{\circ} 48^{\prime} \mathrm{W}$.

5. Britannia Gletscher, the lower station data are representative of conditions over the ablation zone of the glacier. The station was $0.5 \mathrm{~km}$. from the glacier edge but well clear of changes in slope and steeper streams, though towards the end of the ablation season, a deep channel passed near the site. The surface was fairly uniform over $5 \mathrm{~km}$. upwind. $\bar{z}_{0}=0.5 \mathrm{~cm}$. (early summer $z_{0}=0 \cdot 40 \pm 0 \cdot 16$, middle summer $z_{0}=0 \cdot 50 \pm 0 \cdot 3 \mathrm{I}$, late summer $\bar{z}_{0}=0.57$ $\pm 0 \cdot{ }^{\circ}$ ). Lower station: height $460 \mathrm{~m}$., lat. $77^{\circ}$ i $2^{\prime}$ N., long. $23^{\circ} 48^{\prime} \mathrm{W}$.

\section{Application of Existing Laws to Observed Data}

As a first step in finding the coefficient of eddy diffusion for subsequent evaluation of heat and vapour transfer over the various melting ice surfaces, the observed wind-speed profiles were examined to find which law of wind-speed variation with height offered the best fit. When classified into stability groups according to the Richardson number the data confirmed first impressions that unstable conditions were infrequent over melting ice. Highest stabilities $(\mathrm{Ri}>+0.5)$ were found on the Britannia Gletscher, especially at the lower station where low wind speeds $\left(\bar{u}_{200}=\mathrm{I} \cdot 6 \mathrm{~m}\right.$. sec. $\left.{ }^{-1}\right)$ were more frequent. The mean deviation was found from the sum of the separation of observed wind speeds from the best theoretical profile of each wind law that could be drawn for that one hour test. A law which gave a profile that attained an overall mean deviation of less than i i per cent from the mean wind speed of the observed profile was retained: Only those profiles which reached this standard for at least one law were ultimately recognized. 20 per cent of the profiles were outside this criterion; they could be fitted by none of the above laws. Fig. 2 summarizes the relationship of the mean deviation and the goodness of fit of the profiles in respect to site, law and stability.

\section{(a) Suitability of the logarithmic law}

The logarithmic law was most applicable in neutral conditions and, very unexpectedly, in marked inversions also (an example is shown in Figure 3). For each site the surface roughness parameter was evaluated from this law in neutral conditions and has been given with the site descriptions in section III. Roughness parameters of the same order of magnitude have been determined by other workers at similar sites (e.g. Sverdrup, I936; Liljequist, I957; Keeler, I964). The friction velocity, $u_{*}$, was usually within the range 45 to $15 \mathrm{~cm}$. $\mathrm{sec}^{-1}$.

(b) Suitability of the power laws

A power law, and Deacon's modification of it, also fitted the observations fairly well, but, within stability groups, the variation of the power parameters was often quite large as shown 
in Table II and Figure 4. On the frozen lake and at the Swedish sites, the index I $/ n$ for the power law in neutral conditions was approximately $\frac{1}{7}$ which agrees with the empirical value quoted in Section I above, whereas that for the Greenland glacier (the roughest surface) was $\frac{1}{5}$. In the few unstable conditions experienced, the power law index was $\frac{1}{12}$ which also agrees with the value given in Section I but these values were also found for the very stable conditions.

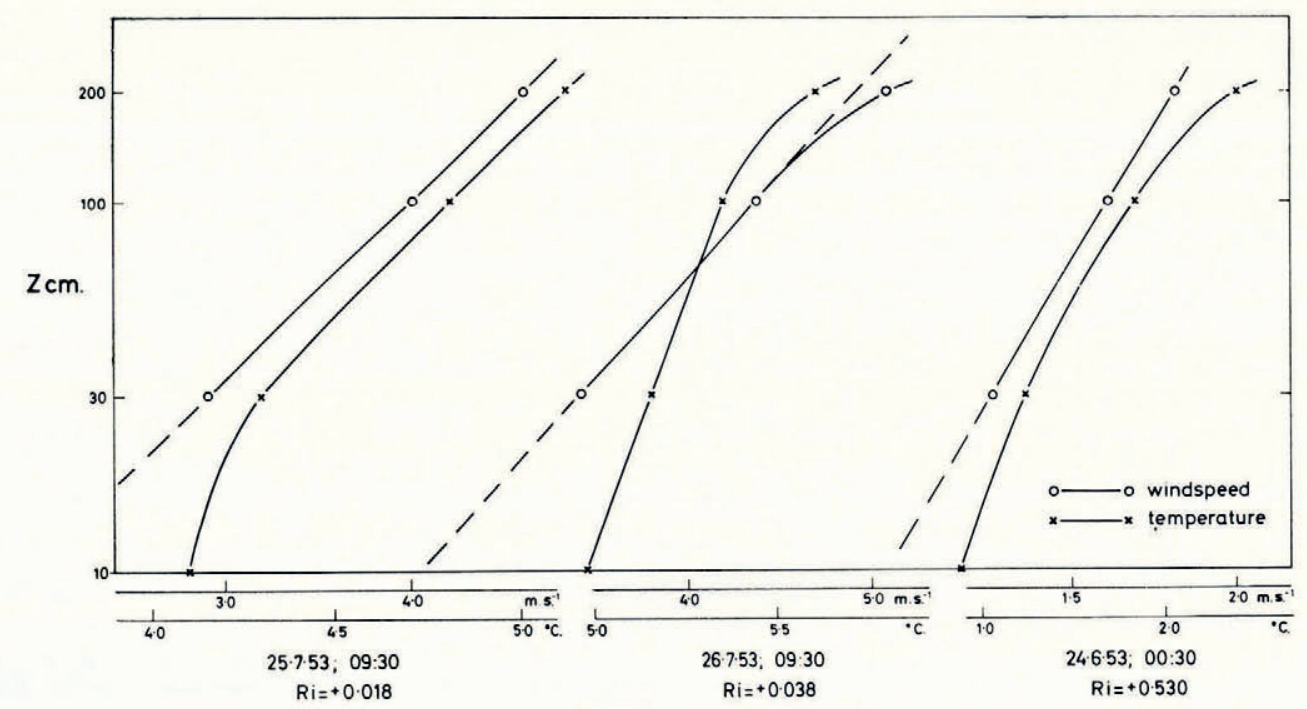

Fig. 3. Wind profiles and associated temperature profiles in various stabilities at the lower glacier site on Britannia Gletscher

Table II. Variation with Stability of Constants in Laws of Wind-Speed Variation with Height

Figures in brackets indicate number of profiles used here.

$$
\begin{array}{lll}
\text { Sites: } & \text { I } & \text { Ice-free surface (Tarfala valley) } \\
& 2 & \text { Storglaciären } \\
& 3 & \text { Frozen lake (Britannia Sø) } \\
& 4 & \text { Britannia Gletscher-upper } \\
& 5 & \text { Britannia Gletscher-lower }
\end{array}
$$

\begin{tabular}{|c|c|c|c|c|c|}
\hline Stability & \multicolumn{2}{|c|}{ Lapse } & Neutral & \multicolumn{2}{|c|}{ Inversion } \\
\hline Richardson number & $\leqslant-0 \cdot 125$ & $\begin{array}{l}-0.0125 \text { to } \\
-0.125\end{array}$ & $\begin{array}{l}-0.0125 \text { to } \\
+0.0125\end{array}$ & $\begin{array}{l}+0.0125 \text { to } \\
+0.125\end{array}$ & $\geqslant 0.125$ \\
\hline $\begin{array}{l}n \\
\text { in power law } \\
\text { expression }(4)\end{array}$ & $\begin{array}{c}9 \cdot 20(2) \\
12 \cdot 50(1) \\
= \\
-\end{array}$ & $\begin{array}{c}6 \cdot 79(\mathrm{IO}) \\
8 \cdot 44(\mathrm{I}) \\
\underline{-} \\
-\end{array}$ & $\begin{array}{l}6 \cdot 16(8) \\
6 \cdot 76(\mathrm{I}) \\
6 \cdot 79(3) \\
4 \cdot 7 \mathrm{I}(29) \\
4 \cdot 83(\mathrm{II})\end{array}$ & $\begin{array}{l}4 \cdot 15(6) \\
6 \cdot 09(2) \\
6 \cdot 45(7) \\
4 \cdot 41(10) \\
5 \cdot 11(39)\end{array}$ & $\begin{array}{r}5 \cdot 46(5) \\
23 \cdot 17(5) \\
6 \cdot 28(4) \\
6 \cdot 35(7) \\
6 \cdot 13(14)\end{array}$ \\
\hline $\begin{array}{l}\beta \\
\text { in Deacon's law } \\
\text { expression (6) }\end{array}$ & $\begin{array}{c}\mathrm{I} \cdot 17(2) \\
\mathrm{I} \cdot 20(\mathrm{I}) \\
= \\
=\end{array}$ & $\begin{array}{c}\mathrm{I} \cdot \mathrm{IO}(\mathrm{IO}) \\
\mathrm{I} \cdot 03(\mathrm{I}) \\
= \\
=\end{array}$ & $\begin{array}{l}\mathrm{I} \cdot 04(8) \\
0 \cdot 93(\mathrm{I}) \\
0 \cdot 97(3) \\
0 \cdot 99(29) \\
\mathrm{I} \cdot 02(\mathrm{II})\end{array}$ & $\begin{array}{l}\mathrm{I} \cdot 00(6) \\
\mathrm{o} \cdot 86(2) \\
\mathrm{O} \cdot 96(7) \\
\mathrm{I} \cdot 04(\mathrm{Io}) \\
\mathrm{I} \cdot 05(39)\end{array}$ & $\begin{array}{l}\mathrm{I} \cdot \mathrm{I} 6(5) \\
\mathrm{I} \cdot \mathrm{I} 4(5) \\
\mathrm{O} \cdot 95(4) \\
\mathrm{I} \cdot \mathrm{I} 4(7) \\
\mathrm{I} \cdot 09(\mathrm{I} 4)\end{array}$ \\
\hline $\begin{array}{l}a \\
\text { in log-plus-linear law I } \\
\text { expression (10) }\end{array}$ & & $\begin{array}{r}+5 \\
= \\
=\end{array}$ & $\begin{array}{r}+5 \\
-73 \\
+14 \\
+14 \\
+14\end{array}$ & $\begin{array}{r}-3 \\
-73 \\
+14 \\
+14 \\
+14\end{array}$ & $\begin{array}{r}-3 \\
-73 \\
? \\
? \\
?\end{array}$ \\
\hline $\begin{array}{l}\gamma^{\prime} \\
\text { in log-plus-linear law } 2 \\
\text { expression }\left(1_{5}\right)\end{array}$ & & $\begin{array}{r}+35 \\
-10 \\
- \\
-\end{array}$ & $\begin{array}{l}+35 \\
-10 \\
+20 \\
-4 \\
-4\end{array}$ & $\begin{array}{l}+35 \\
-10 \\
+20 \\
-4 \\
-4\end{array}$ & $\begin{array}{r}-4 \\
-10 \\
-4 \\
-4\end{array}-$ \\
\hline
\end{tabular}


The $\beta$ value in Deacon's power law (Table II and Fig. 5) was generally greater than unity even in stable conditions. A minimum is suggested for $\beta$ in Figure 5 at what appears to be a critical value of $\mathrm{Ri}=0.2$. It seems that neither the logarithmic nor the power laws are satisfactory through the range of stability experienced over melting ice.

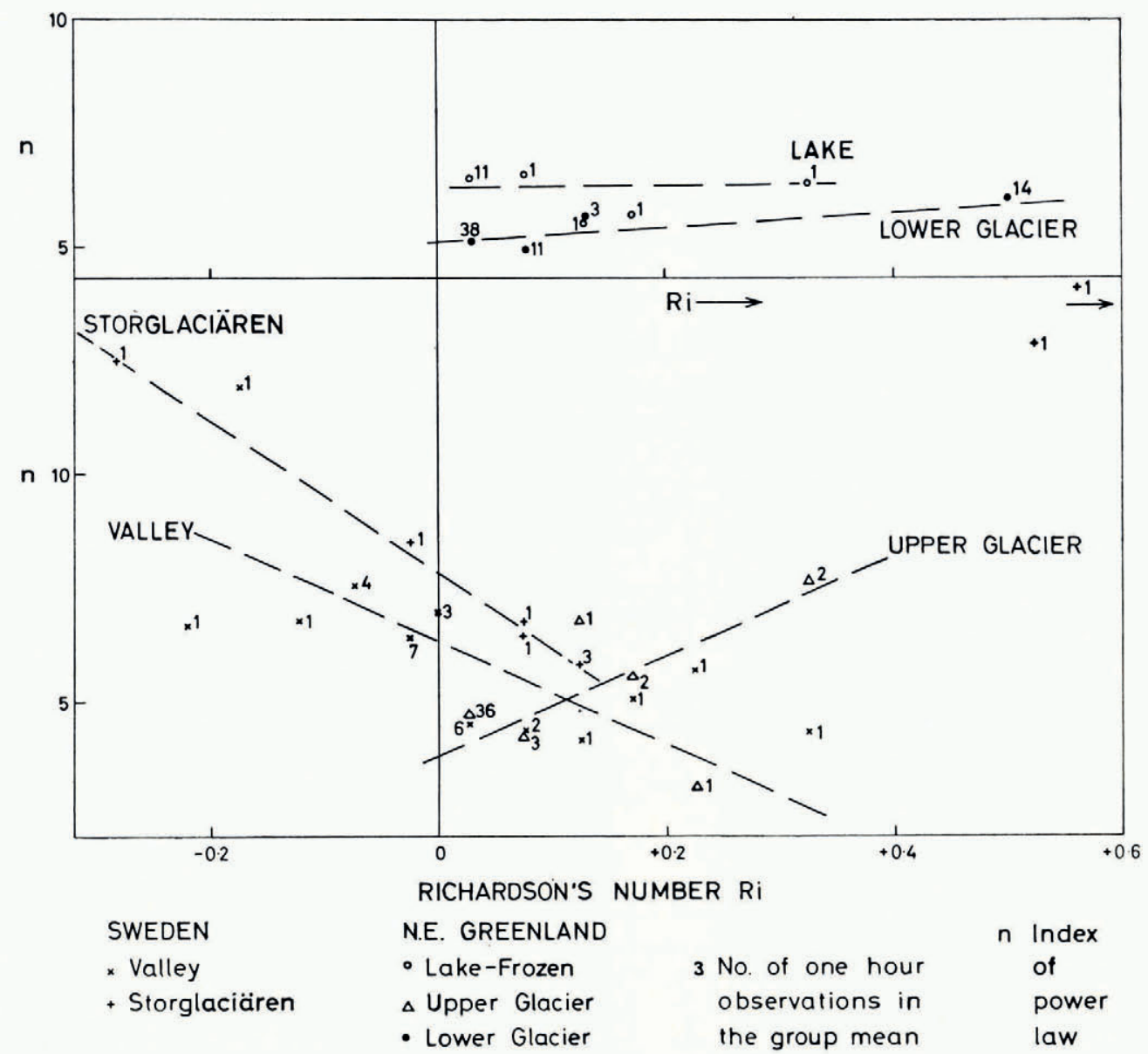

Fig. 4. Variation with stability of the index $n$ in Sverdrup's power law (expression (4))

(c) Suitability of the logarithmic-plus-linear laws

Following Monin and Obukhov's theory, different constants were derived for various stabilities at the six sites. Figure 6 shows the regression between $B$ and $f(\alpha / L)$ for the ice-free valley site. From Table II it appears that $\alpha$ (in expression Io) is not a universal constant. Table II shows a variety of constants evaluated for the second logarithmic-plus-linear law (15). At very great stabilities $\mathrm{Ri}>+0.5$ a relevant constant could not be distinguished and generally this law gave a relatively poor fit. The main difference between these two laws is that for Monin and Obukhov's law the ratio $\alpha / L$ is found from each profile and this ratio determines the remaining velocities at various heights for comparison with observed wind speeds. For the second log-plus-linear law, however, each profile gives $z / L^{\prime}$ (after Panofsky and others, I960), but $\gamma^{\prime}$ must be found graphically from Ellison's relationship between $k / K_{M} *$ 


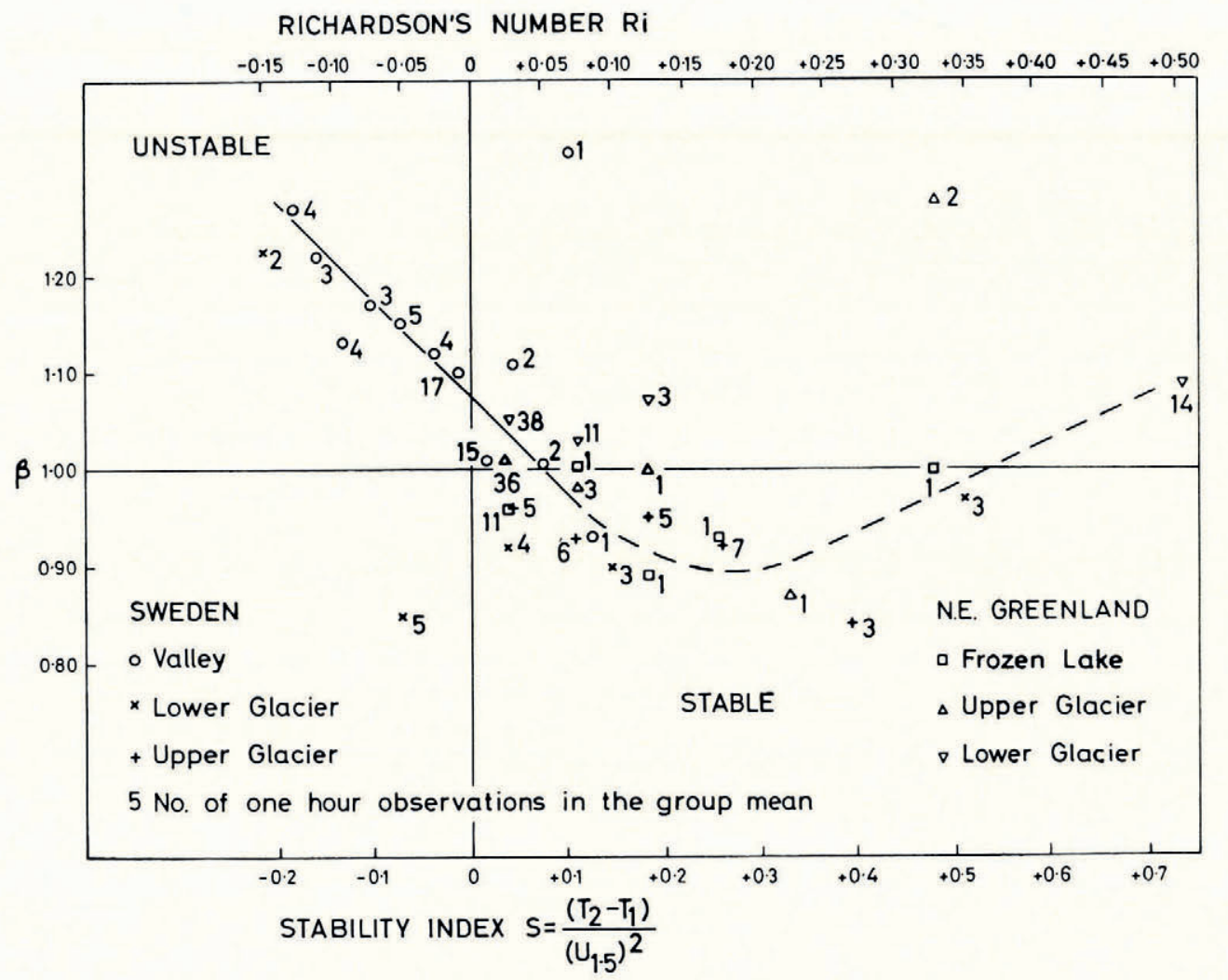

Fig. 5. Variation with stability of the index $\beta$ in Deacon's power law (expression (6))

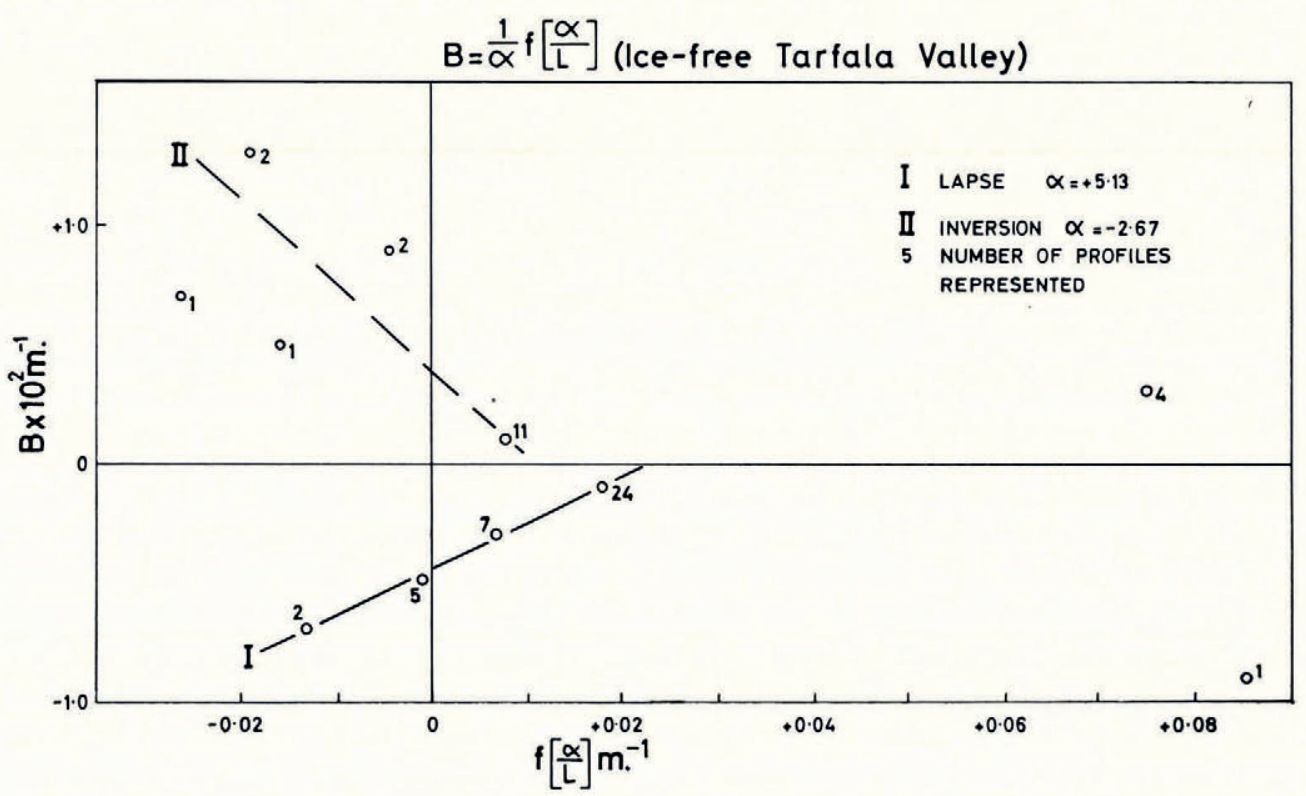

Fig. 6. Variation with stability B of constants in Monin \& Obukhov's logarithmic-plus-linear law (expression (Io)). Data from the ice-free Tarfala valley 
and $z / L^{\prime}$. The applicability of the first law to each profile, is, therefore, independent of a general constant, although this is essential to the second law. Hence the first logarithmic-pluslinear law would be expected to fit individually, better than the second law, as it appears here (Fig. 2).

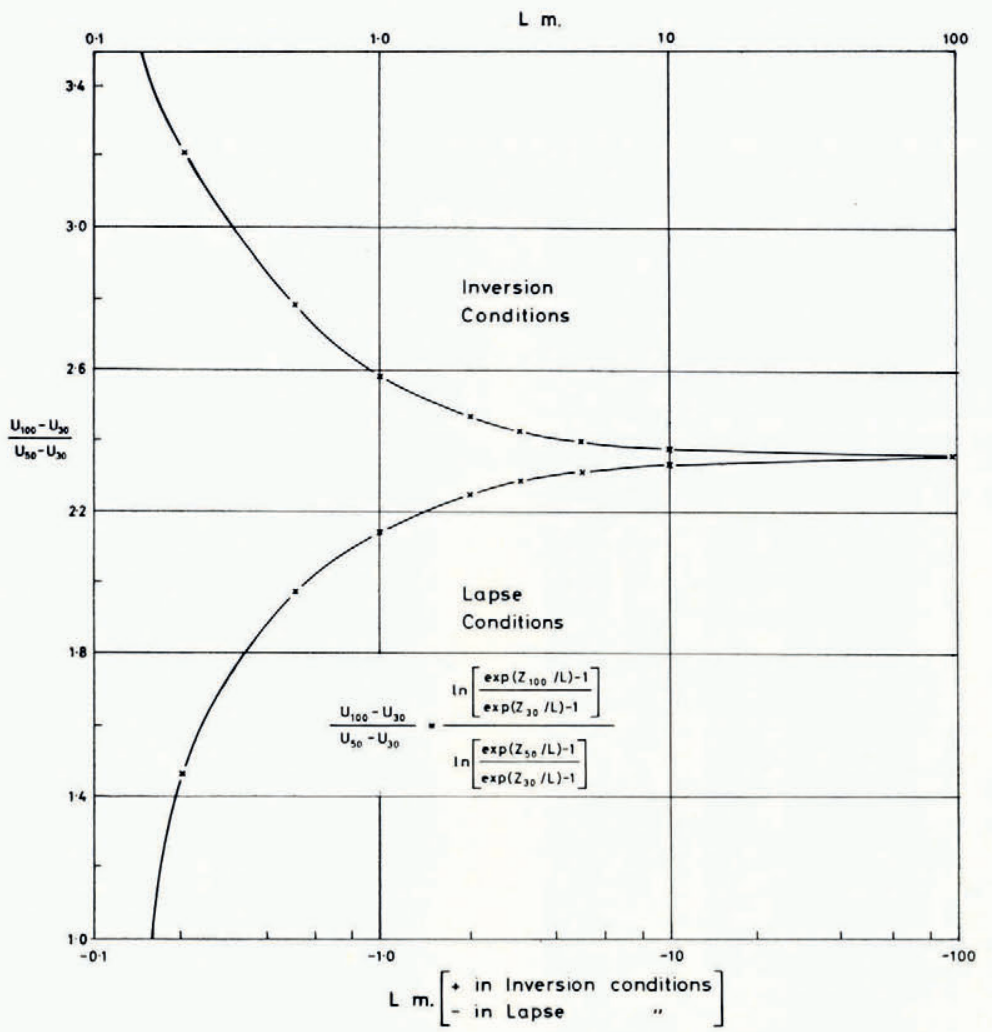

Fig. 7. Variation of $L$ with the ratio of wind-speed differences in Swinbank's exponential law

\section{(d) Suitability of the exponential law}

To apply Swinbank's exponential wind profile (18) directly to the observations, Figure 7 was prepared giving the ratios of wind-speed differences for various values of $L$. Similarly the friction velocities were derived as a function of $L$. From Figure 7 it will be seen that there is a limiting wind ratio for the depth of the air layer concerned. As $L$ increases in neutral stabilities, the extreme ratio of expression (18) becomes

$$
\frac{u_{3}-u_{\mathrm{I}}}{u_{2}-u_{\mathrm{I}}}=\frac{\ln z_{3} / z_{\mathrm{I}}}{\ln z_{2} / z_{\mathrm{I}}}
$$

With $z_{1}, z_{2}$, and $z_{3}=30,50$ and $100 \mathrm{~cm}$. this ratio is $2 \cdot 3^{6}$. Ratios beyond this limit were found to have occurred for some of the inversion conditions but for $3^{8}$ per cent of the wind profiles, a stability index $L$ and a friction velocity $u_{*}$ could be determined. With these values, the velocities at $200 \mathrm{~cm}$. and $10 \mathrm{~cm}$. have been calculated to compare with observed wind speeds at these heights. The mean deviation for all sites considered range from $10 \cdot 2 \mathrm{~cm} . \mathrm{sec} .^{-1}$ over $2 \mathrm{I}$ profiles in adiabatic conditions to $3.2 \mathrm{~cm}$. $\mathrm{sec} .^{-1}$ over 10 profiles in conditions of strong inversion. 
The limit in the number of wind profiles to which the exponential law could be applied precludes a comparison of the fit of the law in the manner used in Figure 2 for comparison of other laws. But the differences between the total mean deviations of the exponential application and of the total mean deviations of the other expressions tried here, are shown in Table III.

Table III. The Differences between Mean Estimates for Wind Speeds (cm. sec. $^{-1}$ ) By the Exponential Expression and that by All Other Laws + indicates that the exponential expression is superior, being nearer the observed value.

\section{Lapse \\ Adiabatic \\ Inversion}

Law of wind-speed variation with height

Logarithmic law

Power law

Deacon's law

Logarithmic + linear law (I)

Logarithmic + linear law (2)

$\begin{array}{cc} & -0 . \mathrm{I} 25 \\ \mathrm{Ri} & <\mathrm{R} \\ -0.125 & -0.0125 \\ +0.69 & +0.24 \\ +\mathrm{I} .50 & +0.35 \\ +\mathrm{I} .09 & +2.46 \\ +0.82 & +4.79 \\ +29.46 & +\mathrm{I} 4.44\end{array}$

-0.0125
$<\mathrm{Ri}$
$+0 \cdot 0125$
$-6 \cdot 68$
$-4 \cdot 71$
$-4 \cdot 98$
$-17 \cdot 41$
$+1 \cdot 00$

-0.0125
$<\mathrm{Ri} \gtrless$

$+0 \cdot 0125$

$-6 \cdot 68$

$-4 \cdot 98$

$+\mathbf{I} \cdot 00$

$\begin{array}{lr}+0.0125 & +0.125 \\ <\mathrm{Ri} & <\mathrm{Ri} \\ +0.125 & \\ -0.06 & -0.08 \\ -0.01 & +0.52 \\ +1.10 & +0.06 \\ -0.55 & +1.13 \\ +4.19 & +380.0\end{array}$

Swinbank's expression is more fitting over the whole stability range than the second loglinear law only, but for all lapse conditions it is the superior expression. There are few profiles in stable conditions to which the exponential form could be applied, but the differences resulting between it and the logarithmic law are very small.

Since fluxes were not available to accompany the wind-speed observations used here, $L$ and $u_{*}$ could not be found independently for comparison with values determined from the exponential function. However, Swinbank (1964, p. I33) used a drag coefficient and wind speeds at low heights to estimate friction velocities and found a very high correlation (0.99) of these with the values derived from his exponential expression; the observations were recorded in convection conditions. From the data in adiabatic and stable conditions analysed here, friction velocities were obtained using the exponential expression for the air layer from Io to $\mathrm{I} O \mathrm{~cm}$. to give the most representative values for each wind profile. These were compared with friction velocities determined from the drag coefficient and wind speeds at $30 \mathrm{~cm}$. (Fig. 8). The correlation coefficient for the II values found by the two methods is 0.56 with a significance level greater than $0 \cdot 001$. This comparatively low coefficient is indicated in Figure 8 by the wide scatter about the unit-gradient line. Generally, the estimates via the exponential function are too low.

Thus, though Swinbank's expressions seem more applicable than any other in lapse conditions, it does not satisfy the observations in a neutral nor in a stable atmosphere. The exponential expression implies a continuously increasing deviation of the wind-speed profile from the logarithmic form as stability intensifies. For the observations considered here, the logarithmic law is satisfactory in neutral and in high stabilities, so here the failure of the exponential law is apparent.

It must be concluded that none of the existing laws are satisfactory. The most difficult part of the range is in the stable region, which is dominant over melting ice. It is thus necessary to look further for one functional expression which would encompass the whole spectrum of stability conditions.

\section{Variation of the Richardson Number with Height}

A problem arising from any form of velocity gradient as a function of the stability gradient is that of integration from the gradient expression to the wind-speed equation when the Richardson number is involved. Priestley (1959, p. 25) assumed that the Richardson number 
varies linearly with height. Deacon (1953, p. 45) similarly suggested that a linear relation would be a good approximation since if

then

$$
\frac{\partial u}{\partial z} \propto z^{-\beta} \quad \text { and } \quad \frac{\partial T}{\partial z} \propto z^{-\lambda}
$$

$$
\mathrm{Ri}=\frac{g}{T_{\mathrm{o}}} \frac{\partial T / \partial z}{(\partial u / \partial z)^{2}} \propto z^{2 \beta-\lambda}
$$

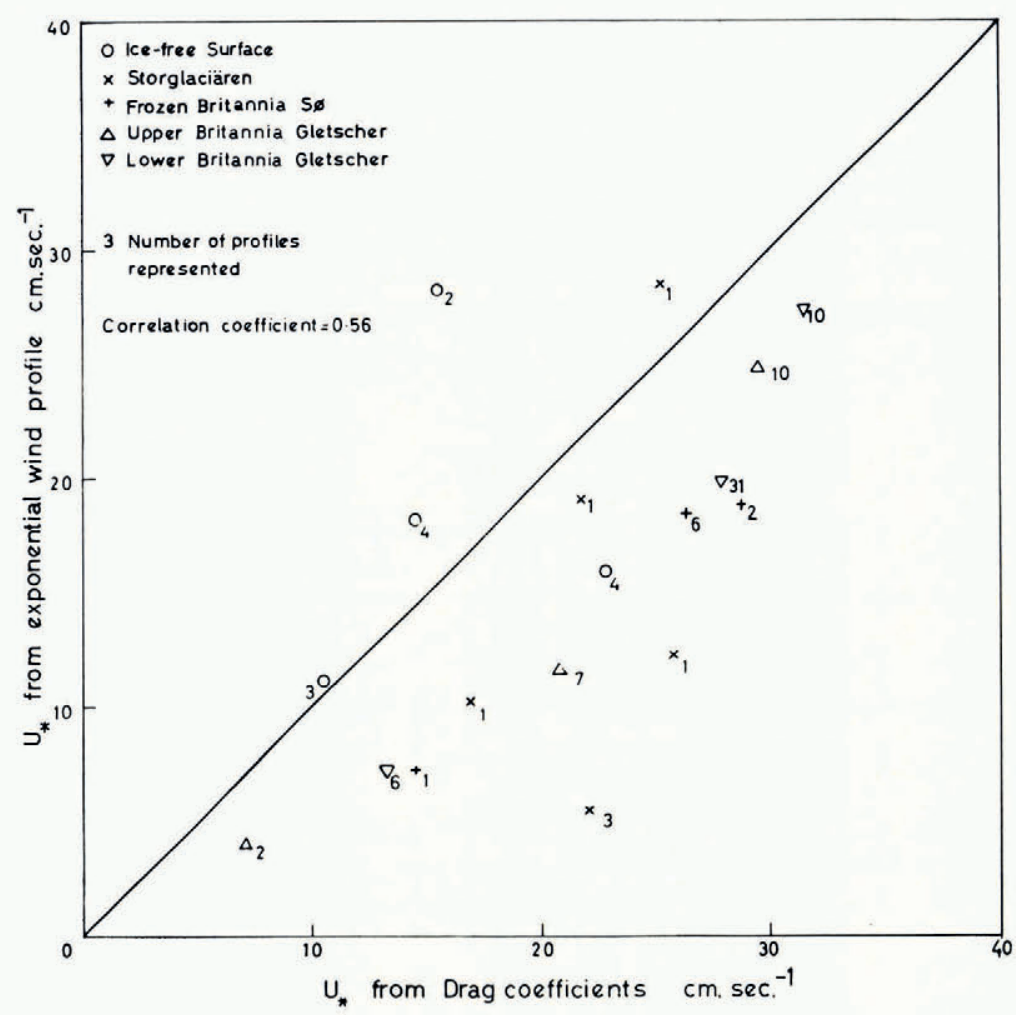

Fig. 8. Comparison of $u_{*}$ found from the exponential law and from the drag coefficient

The power indices are a little different from unity and they do not change by the same amount under different stabilities, so the relation between stability and height though approximately linear may in fact be more complex. No systematic relationship between $\lambda$ and $\beta$, or $\lambda$ and stability was apparent in these observations, so Deacon's expression for the Richardson number could not be employed.

The Richardson number itself can be found rather inaccurately, without an exact mathematical knowledge of the velocity and temperature profiles, by measuring gradients graphically.

As a stability index, only one value of the Richardson number is generally found for a profile, so little data on its variation with height are directly available. However, the Richardson number has been evaluated at 10,30 and $100 \mathrm{~cm}$. for 36 per cent (6o profiles) of the data used here. After grouping into classes, a distinctive pattern can be seen (Fig. 9) in which stability varies as a power of height and the power varies with the mean stability of the 
profile. If $\mathrm{Ri}_{s}$ and $\mathrm{Ri}_{z}$ are the Richardson numbers at a standard height and at height $z$ respectively, then

$$
\mathrm{Ri}_{z}=\mathrm{Ri}_{s}\left(\frac{z}{z_{s}}\right)^{p}
$$

This equation ensures a dimensionally correct function. For all the profiles observed over a $2 \mathrm{~m}$. height interval, the Richardson number had been found at the mean logarithmic height of $55 \mathrm{~cm}$. so $\mathrm{Ri}_{s}$ became $\mathrm{Ri}_{55}$.

From Figure 9 it can be seen that as stabilities increase, gradients decrease until at

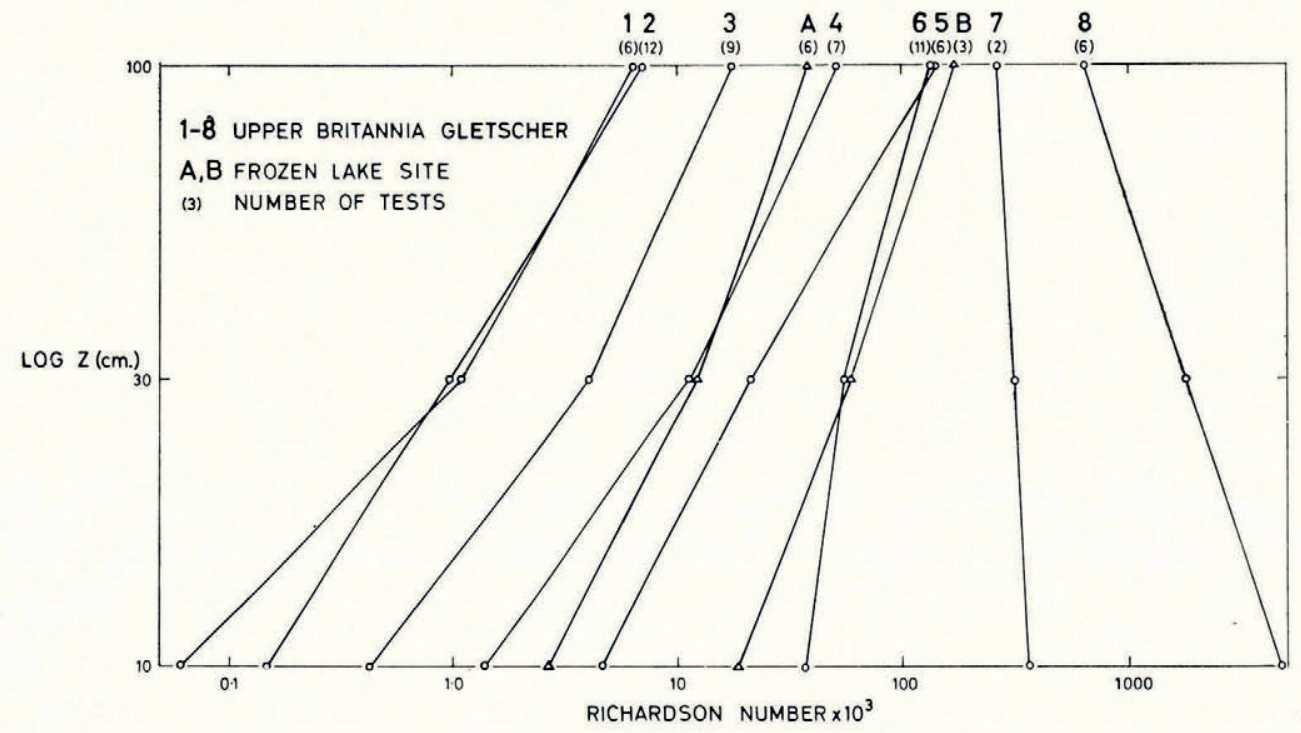

Fig. 9. Variation of Richardson number with height $z$

$\mathrm{Ri} \bumpeq 0.2$ the gradients change sign. Values of $\mathrm{Ri}_{55}$ and $p$ plotted on logarithmic paper show a good linear regression

Hence

$$
p=\mathrm{I} \cdot 3 \mathrm{I} 7 \log _{\mathrm{I0}} \frac{\mathrm{o} \cdot 2}{\mathrm{Ri}_{55}} \text {. }
$$

$$
\mathrm{Ri}_{z}=\operatorname{Ri}_{55}\left[\frac{z}{55}\right]^{\mathrm{I} \cdot 3 \log _{10}\left(0 \cdot 2 /\left|\mathrm{Ri}_{55}\right|\right)}
$$

It may be noted that this expression implies that with $\mathrm{Ri}_{s}=0.2$ stability is constant with height; below this value the power index is positive, $\mathrm{Ri}$ increasing with height. To accommodate temperature lapse conditions, in which $\mathrm{Ri}$ is negative a modulus sign is necessary, hence $\left|\mathrm{Ri}_{55}\right|$ in the power index.

Though there is very little data on the variation of stability with height, Dalrymple's observations at the South Pole give Richardson numbers at I, 2, and $4 \mathrm{~m}$. calculated from differences of observed values rather than from drawn gradients (Dalrymple, and others, 1964, p. 12). The form of the Richardson number used is

$$
\mathrm{Ri}=\frac{g}{T_{0}} \frac{\Delta z \Delta T}{(\Delta u)^{2}} \text {. }
$$


Using the Richardson number obtained at $100 \mathrm{~cm}$. as a standard value, the Richardson number at $200 \mathrm{~cm}$. has been calculated via the power function $(2 \mathrm{I})$ and the linear function

$$
\mathrm{Ri}_{z}=\mathrm{Ri}_{s} \frac{z}{z_{s}} .
$$

The agreement of the calculated with the "observed" Richardson numbers is not very good

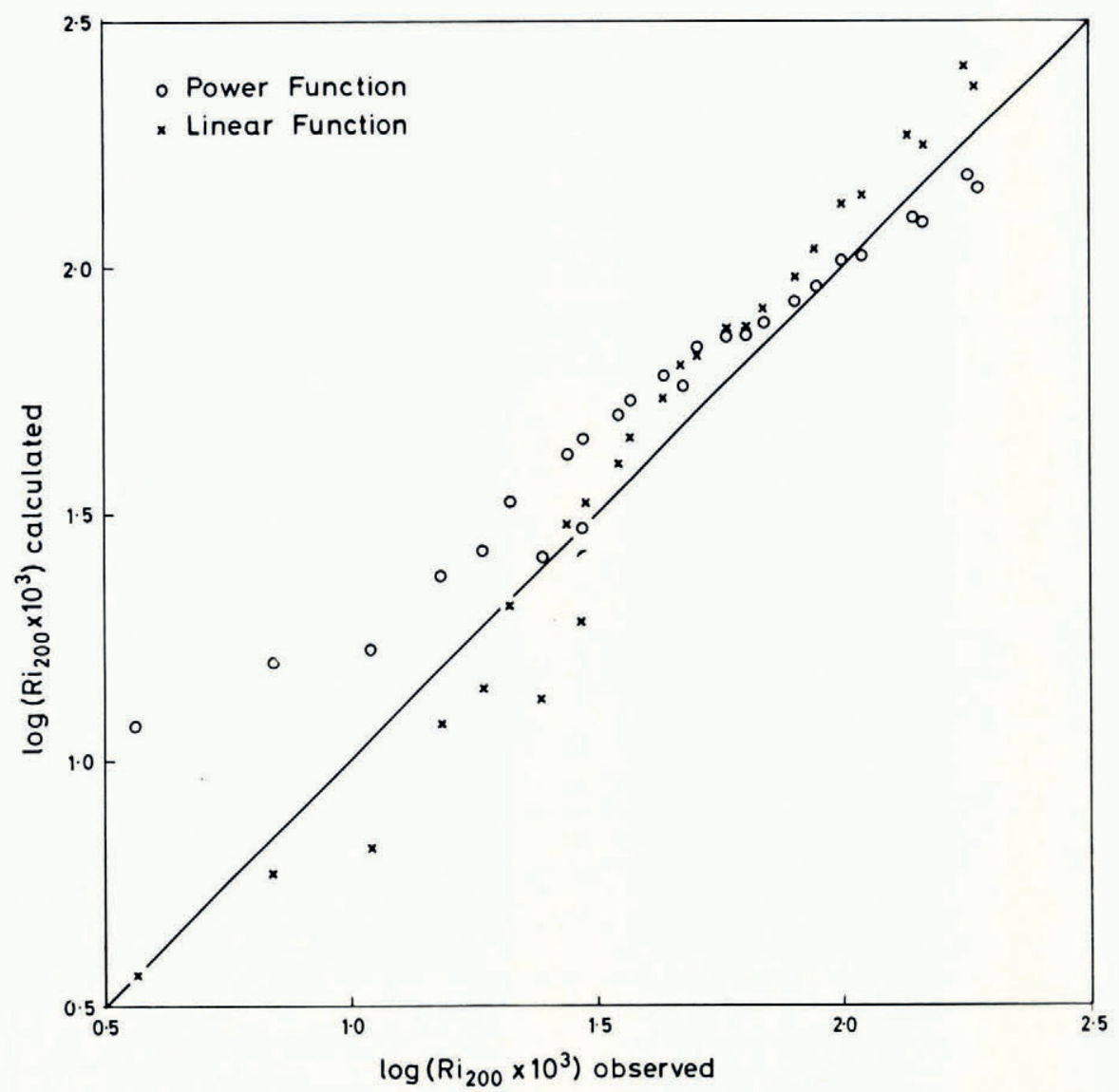

Fig. 1o. Comparison of observed and calculated Ri $i_{200}$ based upon Dalrymple and others' ( $\left.196_{3}\right)$ South Pole data

but the agreement using the power function is slightly superior (Fig. Io). The root-meansquare of the deviations using the power function is 0.013 whereas that of the linear function estimate is 0.025 .

Independent of the characteristic stability of a profile, neutral stability predominates very near the ground. The function suggested here gives this relationship, but does not always indicate an increase of the Richardson number with height. For values greater than $\operatorname{Ri}_{s}=0 \cdot 2$ the maximum value of $\mathrm{Ri}$ must be found at heights less than the standard height. The power function of the variation of Richardson number with height is used in the subsequent analysis of wind-speed profiles. 
Vi Deviation of Wind Speed from the Logarithmic Form as a Function of the Richardson Number

In conditions of free convection, the mixing length (see Section $I(a)$ ) should tend to plus infinity and become zero at some high positive stability where turbulence is precluded. But the deviation from the logarithmic law for these observations over snow and ice has been shown (Fig. 2) to become a minimum at two separate ranges of stability. A cubic form thus seems appropriate (Fig. I I) for the relation of stability to the mixing length and, by differentiation, also for the velocity profile.

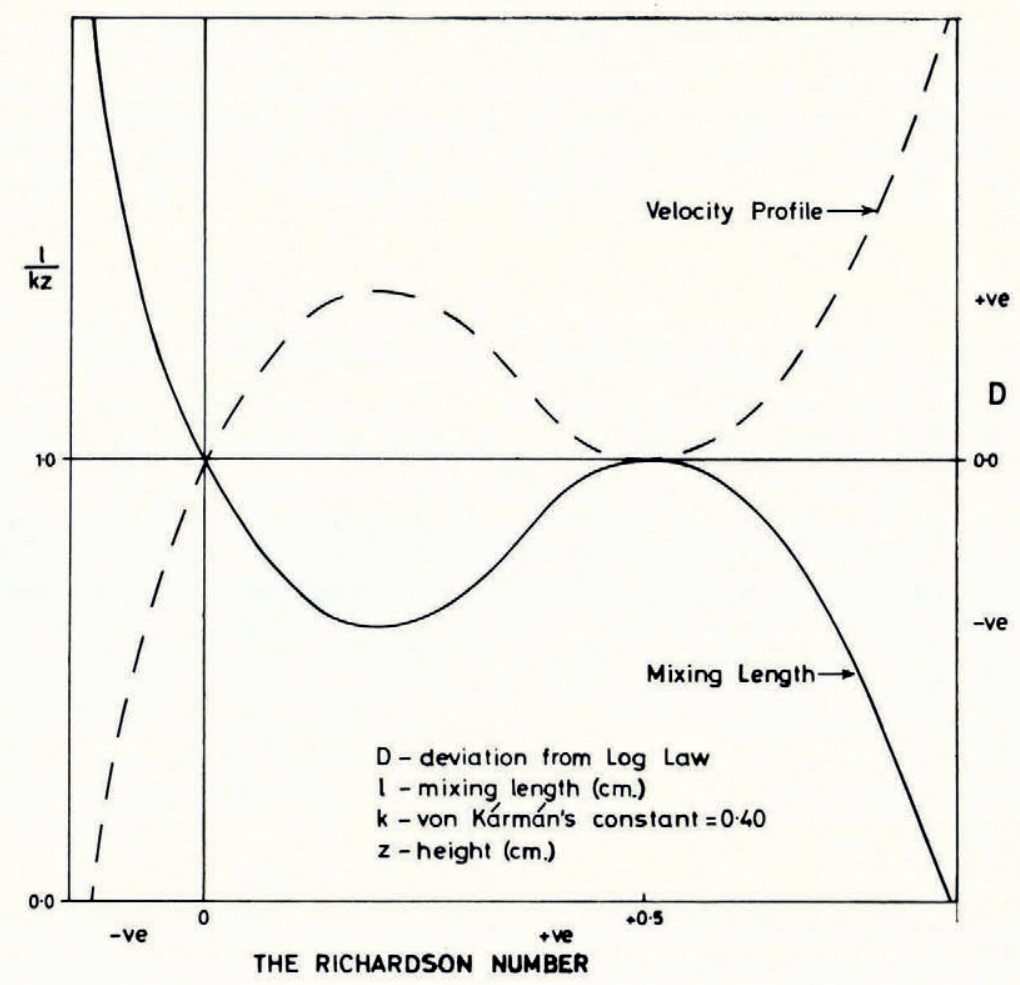

Fig. II. Variation with stability of the mixing length and of the deviation of observed wind profiles from the logarithmic law, implied in Figure 2

The average deviation between observed wind speeds and those velocities determined from the best-fitting logarithmic expression was found for each profile (Section IV). The windspeed deviation from the logarithmic form may be taken as positive in stable, and negative in unstable, atmospheres (similar to Figure I) and may be expressed, for all $z$, as

$$
u-\frac{u_{*}}{k} \ln \frac{z}{z_{0}}=|\delta|
$$

The cubic variation of $\delta$ with the standard Richardson number is apparent in Figure I 2 although it must be noted that dimensionally, $\delta$ is a wind speed. To be pliable differentially, a simpler, dimensionless function is required, such as

$$
u=\frac{u_{*}}{k}\left[\ln \frac{z}{z_{0}}+\Delta\right] \quad \text { where } \Delta=\frac{k}{u_{*}} \delta .
$$


The same logarithmic profiles as used to find $\delta$ also gave $u_{*}$. This used the mean of the wind-speed observations near the surface but assumed the logarithmic distribution applicable. As a check on this, the $u_{*}$ values were also derived from the wind speed at the lowest height of observation and the drag coefficient $u_{*}{ }^{2} / u^{2}$ at that height, assumed to be the same as that found from near-neutral profiles. Figure 13 shows good agreement in most of the values of $u_{*}$ found by these methods. A cubic form of the variation of $\Delta$ with stability seems to be

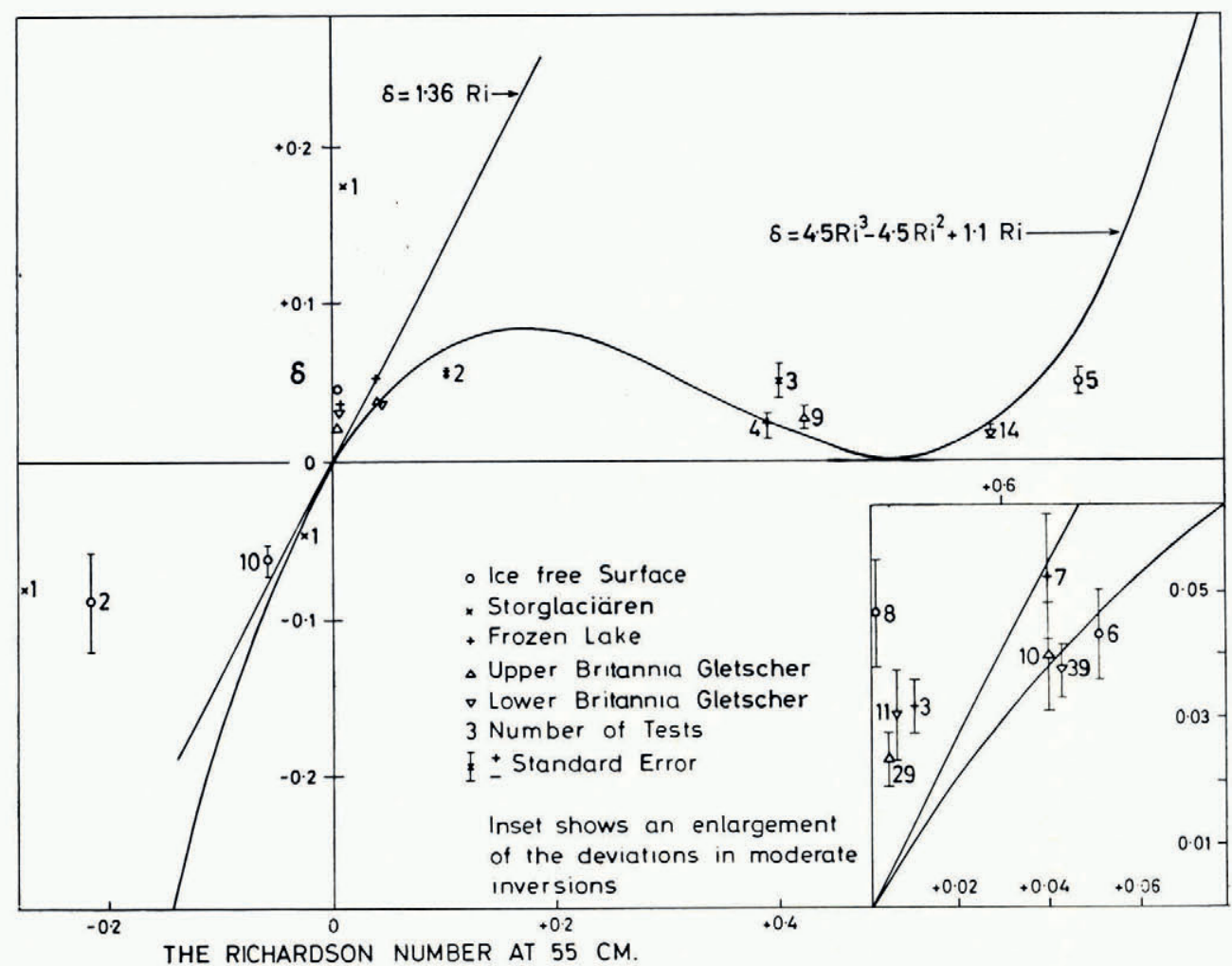

Fig. 12. Variation with stability of the mean deviation $\delta$ in $m . s e c .^{-1}$ of observed wind-speed values from the logarithmic law

required as in Figure I4. A simple linear addition to the logarithmic law, shown by the line through the origin of this graph, is less representative than the cubic form. Hence

$$
u=\frac{u_{*}}{k}\left[\ln \left(\frac{z}{z_{0}}\right)+8 \cdot 4^{8}\left(\mathrm{Ri}^{3}-\mathrm{Ri}^{2}+0 \cdot 25 \mathrm{Ri}\right)\right] .
$$

From this function, differentiation gives an expression for the mixing length

$$
l=k z\left[\mathrm{I}+\mathrm{II} \cdot \mathrm{I} 8 \log { }_{10}\left(\frac{\mathrm{O} \cdot 2}{|\mathrm{Ri}|}\right)\left(3 \mathrm{Ri}^{3}-2 \mathrm{Ri}^{2}+0 \cdot 25 \mathrm{Ri}\right)\right]^{-\mathrm{I}} .
$$

The eddy viscosity from the logarithmic-plus-cubic expression can be found as $K_{M}=u_{*} l$. This expression for the mixing length shown in Figure 15 presents a rather peculiar pattern which differs significantly from that predicted theoretically, and so deters the use of the cubic function; it implies that the function is only representative for the range $-0 \cdot \mathrm{Io}_{0} \leqslant \mathrm{Ri}_{55} \leqslant$ $+0 \cdot 50$. 


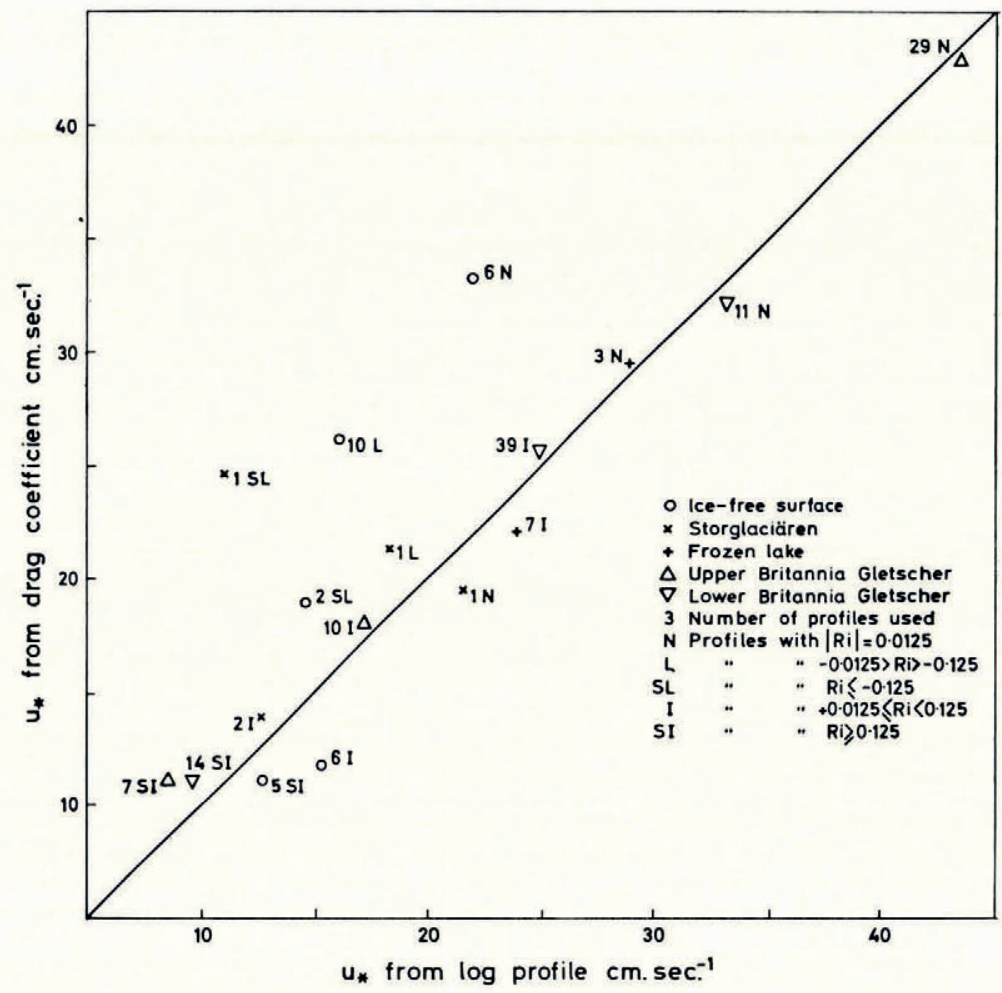

Fig. I3. Comparison of $u_{*}$ found from the logarithmic profile and from the drag coefficient

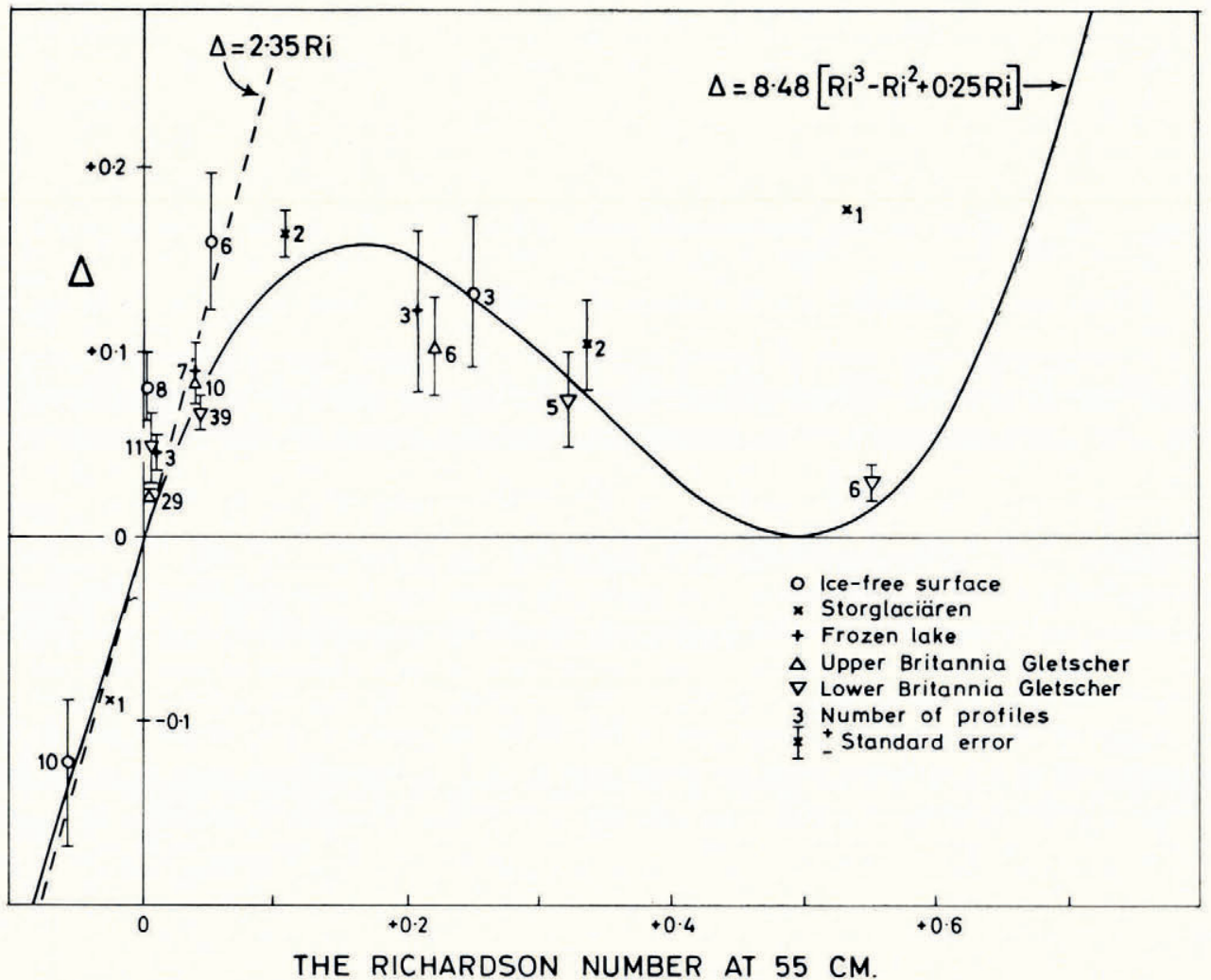

Fig. 14. Variation with stability of the dimensionless mean deviation $\Delta$ of observed wind-speed values from the logarithmic law 
If the expression describing the variation of the Richardson number with height was a more direct one, then an examination of the influence of stability on the velocity profile or on the mixing length would lead to the reciprocal curves postulated in Figure I 1 . Since the velocity function (24) was derived from direct measurements, it appears to be more reliable than the derived mixing length.

VII The Fit of the Logarithmic-Plus-Cubic Expression for Wind Speed with Observed Data

The validity of expression (26) for the velocity profile may be tested by applying it through various stabilities. As mean deviations for groups of profiles were used to solve the function

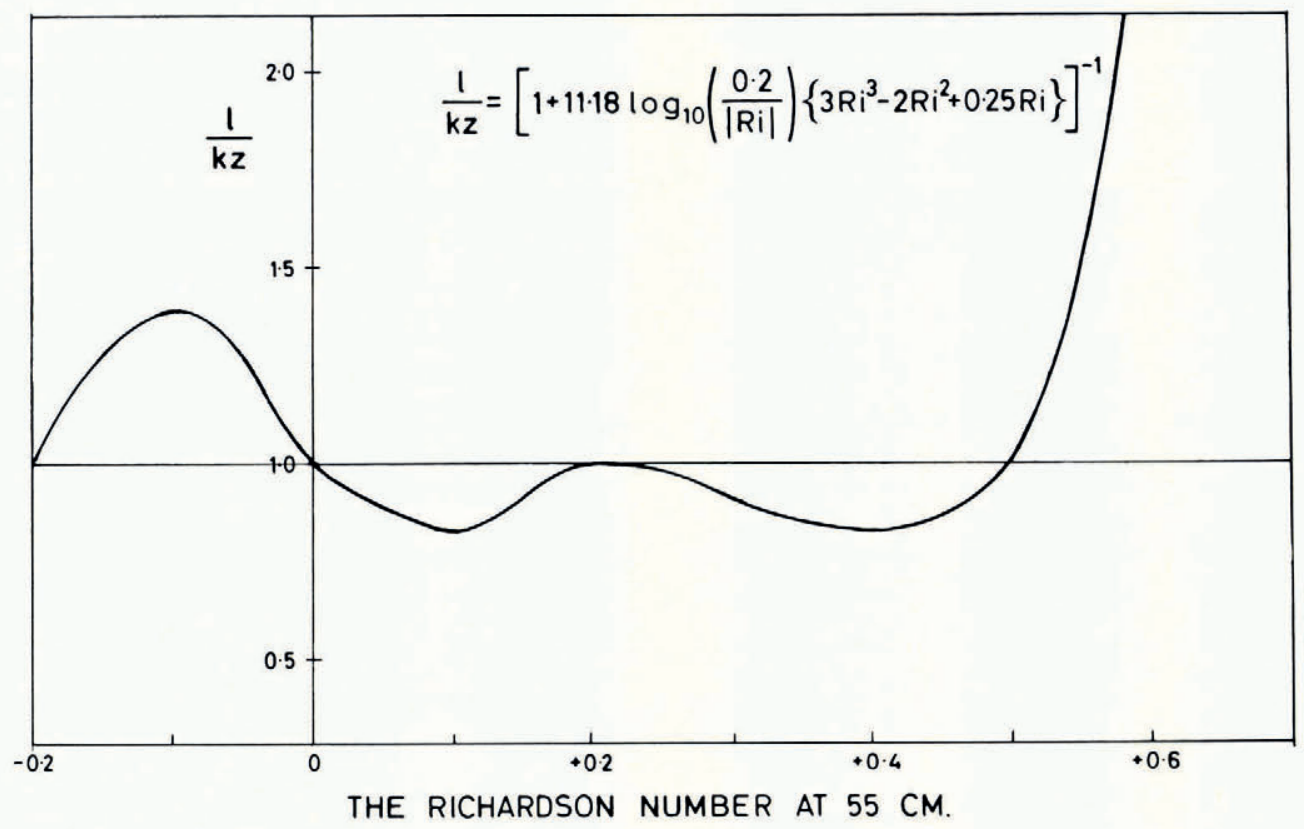

Fig. 15. Variation of the mixing length with stability

it would not be expected to fit individual profiles exactly. The plotted standard errors (Figs. 12 and 14) give some indication of how representative these means are. The goodness of fit of this new expression for the velocity profile depends also on the form of the variation of Richardson number with height and on the estimated friction velocity $u_{*}$. Accepting the power expression (2I) for the Richardson number, a mean value of $u_{*}$ was found for each profile, which was then applied in expression (26). The last section of Figure 2 shows the difference between the observed and the calculated profile. It will be seen that the logarithmic-plus-cubic law is only slightly superior to the second logarithmic-plus-linear law.

Under strong inversions, with their normally low wind speeds, errors arise more readily through the actual recording of the values. In this stability region a relatively larger sample than that indicated in Figures 12 and 14 may be required to represent these extreme conditions, which would mean that from the data available only those near adiabatic conditions $(|\mathrm{Ri}| \leqslant 0 \cdot \mathrm{I})$ are justifiably worth using. Within this reduced range a linear expression would be preferably for the relation between $\delta$ (also $\Delta$ ) and stability (Figs. I2 and 14). Such a function would be very similar to the logarithmic-plus-linear law of Monin and Obukhov 
discussed above. The difficulties of expansion need not arise with this wind-speed expression, for it is not raised to a fractional power, and limitations of the mixing length would be less severe. This straight-line function, forming the logarithmic-plus-linear relationship, is the limiting tangent at the origin of the cubic form already used.

\section{ViII The Laws of Wind-Speed Variation with Height and the Coefficient of Eddy Viscosity}

Of the seven wind-speed laws compared here, the logarithmic law appears superior in strong inversions as well as in adiabatic conditions and generally may be considered the most applicable for observations in the lowest $2 \mathrm{~m}$. above a melting ice surface. The exponential law, though superior for lapse conditions can be difficult near neutral and in part of the stable range. It requires great precision in observation for satisfactory parameters to be determined. A power law and logarithmic-plus-linear law of the first type (Fig. 2) fit observations almost equally well in moderately stable conditions but these laws have the difficulties, discussed above, of changes in the constants used. Furthermore the selection of a particular law determines different values for eddy viscosity, the most extreme values deriving from the power laws (Table IV). Logarithmic or power laws have generally been used in evaluation of components in the heat balance at a glacier surface; the choice of law has a very marked effect on the conclusions.

Table IV. Coefficients of Eddy Diffusion for Momentum $\left(\right.$ м. $^{2}$ sec. $^{-1}$ ) At 0.5 м.

(Figures in brackets indicate number of profiles used.)

$\quad \begin{aligned} & \text { Law of wind-speed } \\ & \text { variation with height }\end{aligned}$
Logarithmic law
Power law
Deacon's law
Logarithmic + linear law (I)
Logarithmic + linear law (2)
Exponential law
Logarithmic + cubic law
Average $K_{M}$ (excluding
power laws)

Law of wind-speed

Logarithmic law

Power law

Logarithmic + linear law (I)

Logarithmic + linear law (2)

Exponential law

Average $K_{M}$ (excluding power laws

\begin{tabular}{|c|c|c|c|c|}
\hline $\begin{array}{l}\mathrm{Ri} \gtrless \\
-0.125\end{array}$ & $\begin{array}{l}-0 \cdot 125 \\
<\mathrm{Ri} \\
-0 \cdot 0125\end{array}$ & $\begin{array}{l}-0.0125 \\
<\mathrm{Ri} \\
+0.0125\end{array}$ & $\begin{array}{l}+0.0125 \\
<\mathrm{Ri} \& \\
+0.125\end{array}$ & $\begin{array}{c}\mathrm{Ri} \\
>+0 \cdot 125\end{array}$ \\
\hline $0.0268(3)$ & 0.0326 (I I) & $0.0730\left(5^{2}\right)$ & $0.0442(64)$ & $0.0196(35)$ \\
\hline $0.0118(3)$ & $0.0103(\mathrm{II})$ & $0.0107\left(5^{2}\right)$ & $0.0082(64)$ & $0.005^{2}(35)$ \\
\hline $0.1237(2)$ & 0.0882 (I I) & $0.0846(51)$ & $0.0678(63)$ & 0.0701 ( 35$)$ \\
\hline $0.0071(2)$ & $0 \cdot 025^{1}(9)$ & $0.0924(50)$ & $0.0281(60)$ & $0.0216(26)$ \\
\hline $0.0465(\mathrm{I})$ & o.0349 (9) & $0.0745(48)$ & o.0466 (59) & o.0195 (22) \\
\hline 0.0902 (3) & $0.075^{2}(5)$ & $0.0436(26)$ & $0.0297(48)$ & 0.0094 (12) \\
\hline o.0499 (3) & 0.0545 (I I) & $0.0823\left(5^{2}\right)$ & $0.0429(64)$ & $0.0236(18)$ \\
\hline 0.0468 (12) & $0.0416(45)$ & $0.0763(228)$ & 0.0388 & o.oig6 ( I I \\
\hline
\end{tabular}

The eddy viscosity appears to change significantly with stability except in the case of Deacon's derivation in which the inconsistent variation of $\beta$ with the Richardson number would become important.

The variation of eddy viscosity with stability as shown in Table IV has already been indicated, for the logarithmic-plus-cubic form of wind-speed variation, in Figure 15 as $1 / k z$ since from Section I (a) and (c)

therefore

$$
u_{*}=l \frac{d u}{d z} \quad \text { and } \quad K_{M} *=\frac{K_{M}}{u_{*} z}=\frac{u_{*}}{k d u / d z},
$$

$$
K_{M} *=l / k .
$$

The pattern from Figure ${ }_{5} 5$ is shown in Figure ${ }_{1} 6$ as the expected variation of $K_{M} *$ to compare with the dimensionless eddy viscosity found from (28). The simple form of the latter tends to confirm the applicability of the logarithmic expression to wind-speed profiles over a wide range of the stable atmosphere. 
The variable eliminated in the use of $K_{M}{ }^{*}$, the friction velocity, varies significantly with stability (Fig. I7). It decreases rapidly as stability begins to increase from zero to approximately $\mathrm{Ri}=0 \cdot 2$. Values for the eddy viscosity in Table IV reflect this decrease in the friction velocity, and hence the shearing stress, from neutral stability to very low values at more extreme stability.

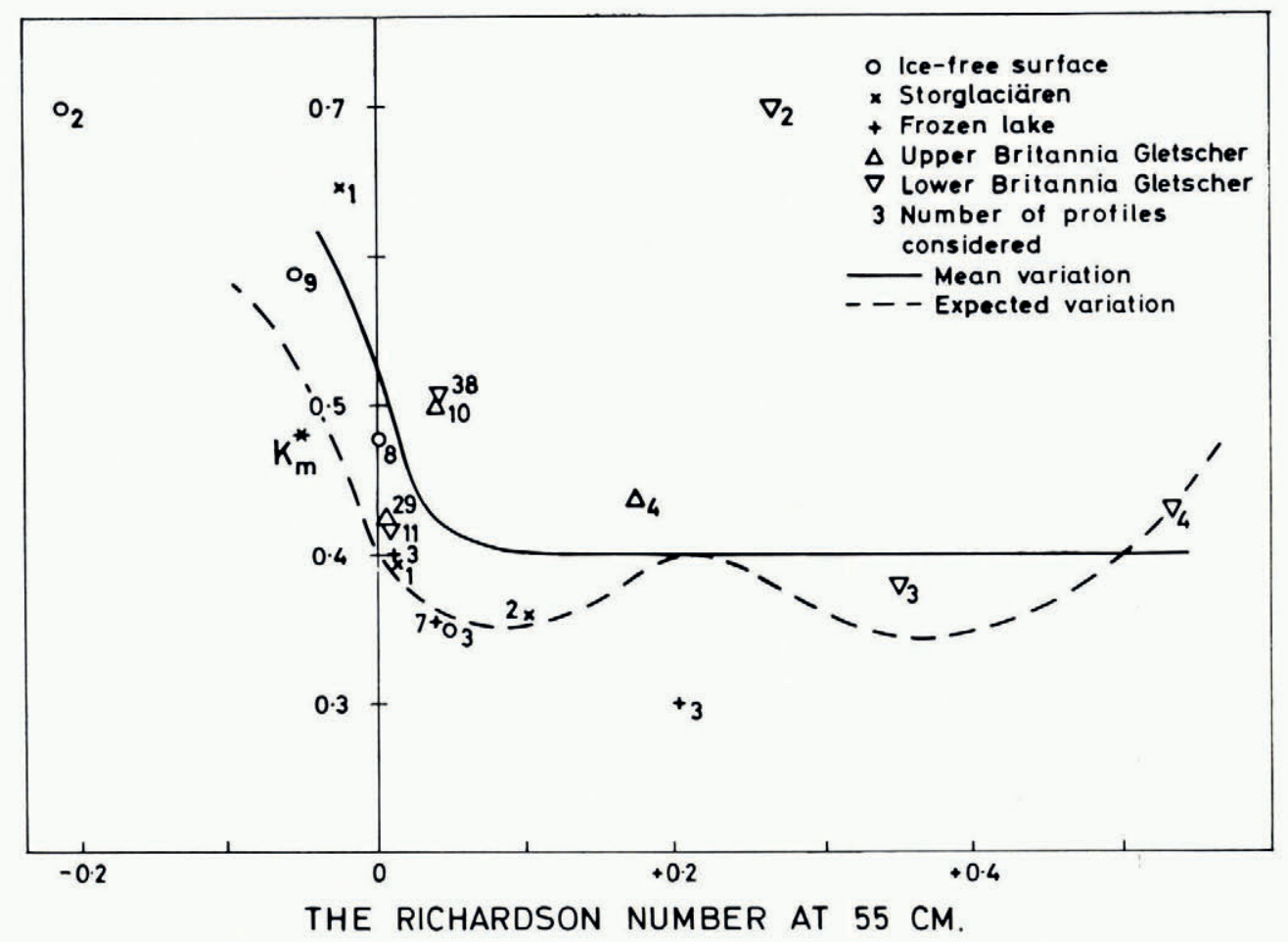

Fig. 16. Variation of $\kappa_{M} *$ with stability

Such change in eddy coefficients over melting ice is important in the heat-balance calculations and conclusions drawn in association with melt-water supply and with climatic change. Increase in air temperature so affects the wind-speed profile that momentum transfer (and probably heat and vapour transfer) may be reduced, which further raises the general importance of radiation in these considerations.

Further work is required in assessing the variation with height of shearing stress and Richardson number before satisfactory comparisons of eddy coefficients and the dependent heat and water balance can be made over glacier surfaces. Until a better approach is possible it seems that the simple logarithmic law of wind-speed variation with height and the direct eddy viscosity is most applicable over a wide range of stability conditions.

\section{Acknowledgements}

The authors must record their thanks to people who have helped with the observations both in the field and in the office and are grateful to Dr. Valter Schytt of Geografiska Institutionen, Stockholms Högskola, for facilities and assistance at their Tarfala field station. The financial support of the Natural Environment Research Council is very much appreciated 
and the help of members of various departments in the University of Newcastle upon Tyne is gratefully acknowledged, particularly Mr. E. N. Quenet who draughted the diagrams.

\section{$M S$. received $I_{1}$ August ${ }_{19} 6_{4}$ and in revised form ${ }_{13}$ August ${ }_{19} 65$}

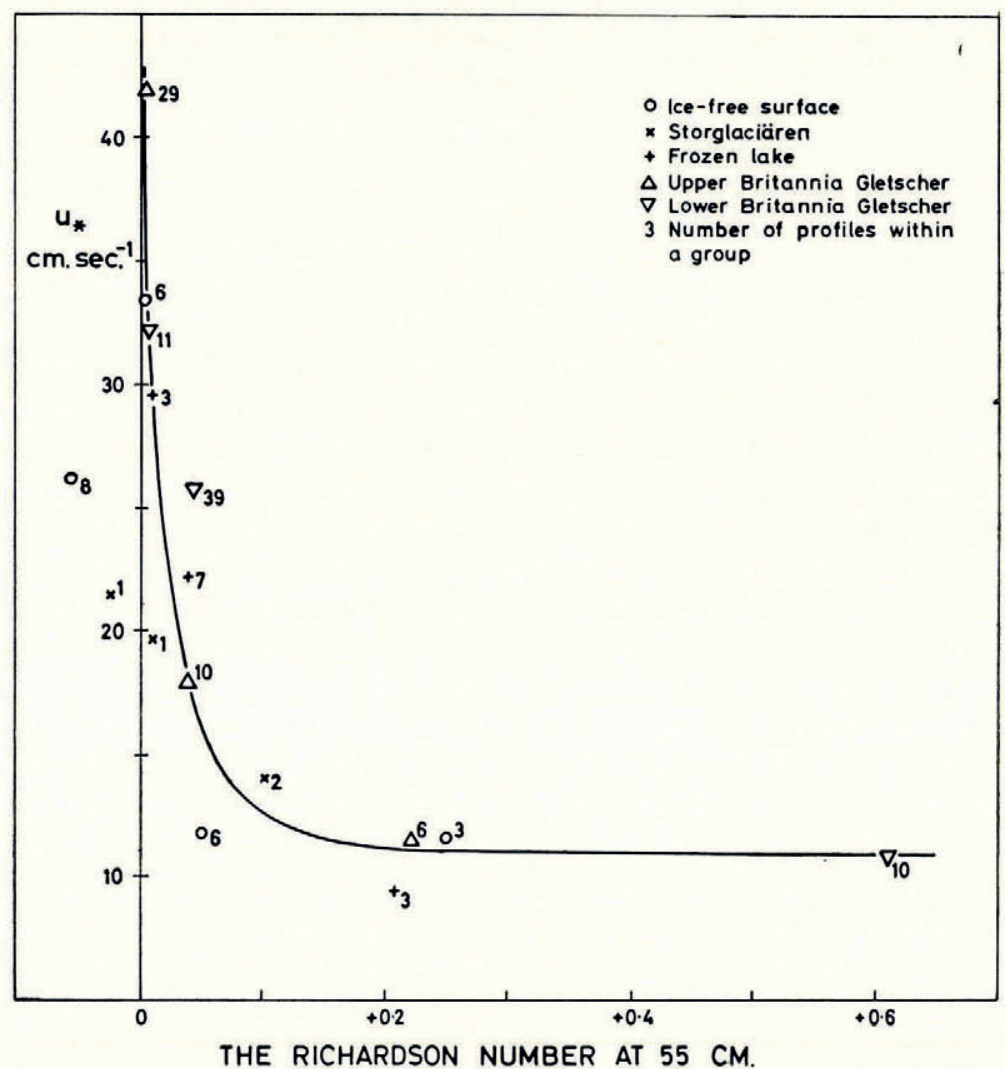

Fig. I7. Variation with stability of friction velocity $u_{*}$ found from wind profiles

\section{REFERENGES}

Brunt, D. 1939. Physical and dynamical meteorology. Second edition. Cambridge, Cambridge University Press.

Caisley, B., and others. 1963. Measurement of profiles of wind speed, temperature and vapour pressure near to the ground, by B. Caisley, H. Lister and L. Molyneux. Union Géodésique et Géophysique Internationale. Association Internationale d'Hydrologie Scientifique. Assemblée générale de Berkeley, 19-8-31-8 1963 . Commission des Neiges et des Glaces, p. 37-48.

Dalrymple, P. C., and others. 1963. South Pole micrometeorology program. Part II. Data Analysis, by P. C. Dalrymple, H. H. Lettau and S. H. Wollaston. U.S. Quartermaster Research and Engineering Center, Earth Sciences Division, Natick, Mass. Technical Report L.S.7.

Deacon, E. L. 1949. Vertical diffusion in the lowest layers of the atmosphere. Quarterly fournal of the Royal Meteorological Society, Vol. 75, No. 323, p. 89-103.

Deacon, E. L. 1953. Vertical profiles of mean wind in the surface layers of the atmosphere. Geophysical Memoirs (London, Meteorological Office), No. $9 \mathrm{I}$.

Deacon, E. L. 1962. Aerodynamic roughness of the sea. Journal of Geophysical Research, Vol. 67, No. 8, p. 3167-72.

Ellison, T. H. 1957. Turbulent transport of heat and momentum from an infinite rough plane. Fournal of Fluid Mechanics, Vol. 2, Pt. 5, p. 456-66.

Keeler, C. M. I964. Relationship between climate, ablation and run-off on the Sverdrup Glacier 1963, Devon Island N. W. T. Arctic Institute of North America, Research Paper No. 27. 
Liljequist, G. H. 1957. Energy exchange of an Antarctic snow-field. Wind structure in the low layer (Maudheim, $\left.71^{\circ} 3^{\prime} \mathrm{S},{ }_{10}^{\circ} 56^{\prime} \mathrm{W}\right)$. Norwegian-British-Swedish Antarctic Expedition, 1949-52. Scientific Results (Oslo, Norsk Polarinstitutt), Vol. 2, Pt. IC, p. 185-234.

Lister, H., and Taylor, P. F. 1961. Heat balance and ablation on an Arctic glacier. Meddelelser om Gronland. Bd. 158, Nr. 7.

Monin, A. S., and Obukhov, A. M. 1954. Osnovnyye zakonomernosti turbulentnogo peremeshiveniya v prizemnom sloye atmosfery. [Basic irregularity in turbulent mixing in the surface layer of the atmosphere]. Akademiya Nauk SSSR. Geofizicheskiy Institut, Trudy [U.S.S.R. Academy of Sciences, Works of the Geophysical Institute], No. 24 ( $15 \mathrm{I})$, p. $163-87$.

Panofsky, H. A., and others. i96o. The diabatic wind profile, by H. A. Panofsky, A. K. Blackadar and G. E. McVehil. Quarterly Journal of the Royal Meteorological Society, Vol. 86, No. 369, p. 390-98.

Pasquill, F. I949[a]. Eddy diffusion of water vapour and heat near the ground. Proceedings of the Royal Society, Ser. A, Vol. 198, No. 1052, p. i $16-40$.

Pasquill, F. I949[b]. A portable indicating apparatus for the study of temperature and humidity profiles near the ground. Quarterly Journal of the Royal Meteorological Society, Vol. 75, No. 325, p. 239-48.

Priestley, C. H. B. 1959. Turbulent transfer in the lower atmosphere. Chicago, University of Chicago Press.

Sutton, O. G. 1932. Note on variation of the wind with height. Quarterly Journal of the Royal Meteorological Society, Vol. 58, No. 243 , p. $74-76$.

Sutton, O. G. 1953. Micrometeorology. New York, McGraw-Hill.

Sverdrup, H. H. 1936. The eddy conductivity of the air over a smooth snowfield. Geofysiske Publikasjoner, Vol. I I, No. 7, p. 5-49.

Swinbank, W. C. r 964 . The exponential wind profile. Quarterly Journal of the Royal Meteorological Society, Vol. 9o, No. 384 , p. $119-35$.

Taylor, R. G. 1960. Similarity theory in the relation between fluxes and gradients in the lower atmosphere. Quarterly Journal of the Royal Meteorological Society, Vol. 86, No. 367, p. 67-78.

Wallén, C. C. 1948. Glacial-meteorological investigations on the Kårsa glacier in Swedish Lappland 1942-1948. Geografiska Annaler, Årg. 3o, Ht. 3-4, p. 451-672.

Yamamoto, G. 1959. Theory of turbulent transfer in non-neutral conditions. Fournal of the Meteorological Society of Japan, Ser. 2, Vol. 37 , No. 2, p. 6o-70. 